[Institut für Chemie und Dynamik der Geosphäre 3: Atmosphärische Chemie
A Comparison of Measured OH Concentrations with Model Calculations 



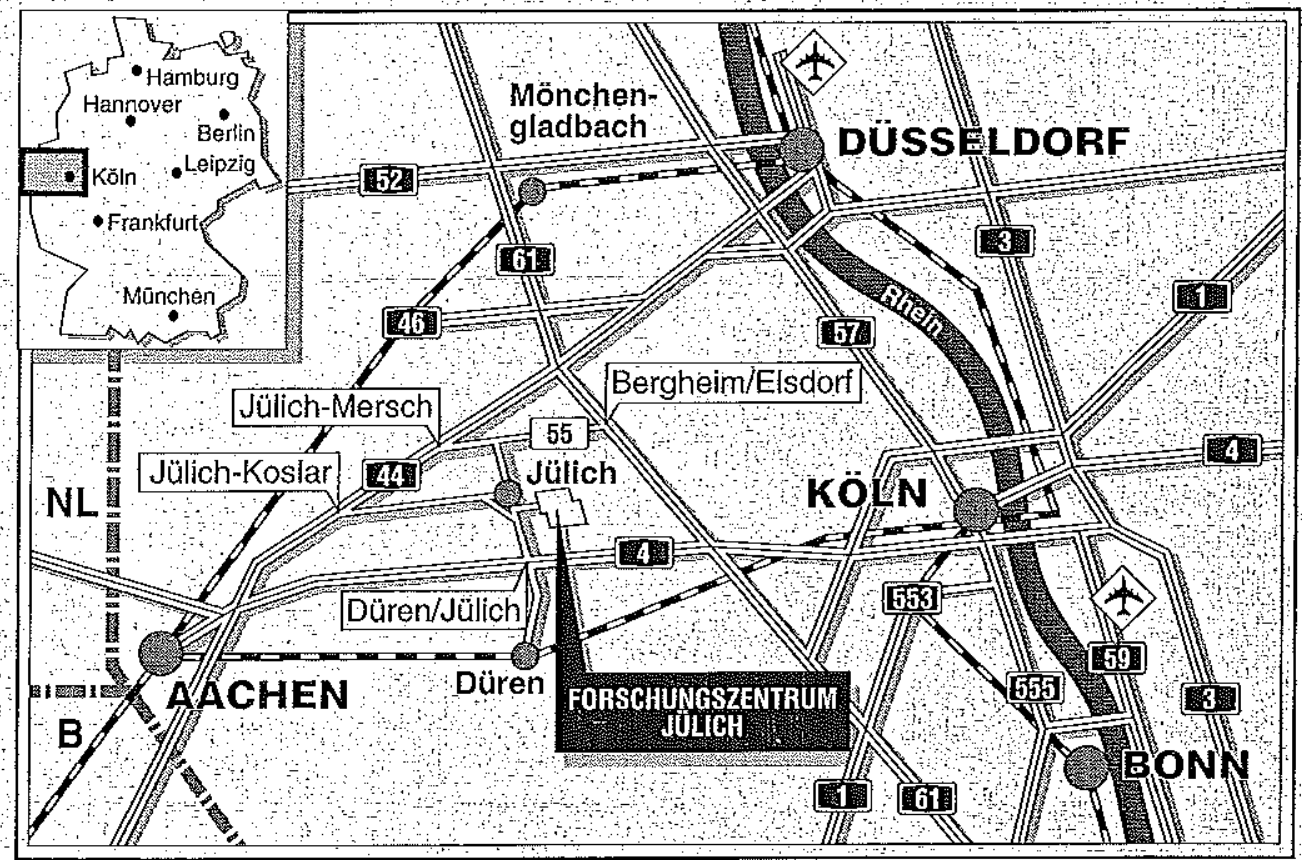

Berichte des Forschungszentrums Jülich, 2951 ISSN 0944-2952

Institut für Chemie und Dynamik der Geosphäre 3 .

Atmosphärische Chemie Jül-2951

Zui beziehen durch: Forschungszentrum Jülich $\mathrm{GmbH}:$ Zentralbibllothek D-52425. Jülich Bundesrepublik Deutschland

Telefon: $02461 / 61-6102$-Telefax:02461/61-6103 Telex: $833556-70 \mathrm{kfa}$ d 


\section{A Comparison of Measured OH Concentrations with Model Calculations}

D. Poppe, J. Zimmermann, R. Bauer, T. Brauers, D. Brüning, J. Callies, H.-P. Dorn, A. Hofzumahaus, F.-J. Johnen, A. Khedim, H. Koch, R. Koppmann, H. London, K.-P. Müller, R. Neuroth, Ch. Plaß-Dülmer, U. Platt, F. Rohrer, E.-P. Röth, J. Rudolph, U. Schmidt, M. Wallasch, D. H. Ehhalt 


\section{Abstract}

The influence of chemical precursors and sunlight on the atmospheric $\mathrm{OH}$ abundance is investigated by a comparison of locally measured tropospheric $\mathrm{OH}$ concentration with model calculations. The latter are based on the gas phase reaction mechanism of the Regional Acid Deposition Model (RADM2) which incorporates an explicit inorganic and a comprehensive organic chemistry. The experimental data were obtained in the planetary boundary layer during two sets of campaigns. In Deuselbach (1983) and Schauinsland (1984) rural conditions were encountered with $\mathrm{NO}_{x}$ concentrations on the average of $2.2 \mathrm{ppb}$ and $0.9 \mathrm{ppb}$, respectively. This data set was already compared with model calculations based upon an older and less detailed chemical reaction scheme (Perner et al., 1987). Since then the experimental data were reanalysed leading to modified measured $\mathrm{OH}$ concentrations and also to modified precursor concentrations. For a consistent comparison with the more recent campaigns in Jülich (1987 and 1988) we have redone the calculations.

The modeled and measured $\mathrm{OH}$-concentrations of the campaigns in 1983 and 1984 correlate well with a coefficient of correlation of $r=0.73$. The model overpredicts $\mathrm{OH}$ by about $20 \%$. Under more polluted conditions in Jülich with average $\mathrm{NO}_{x}$ concentrations of $4 \mathrm{ppb}$ the correlation coefficient between experimental and modeled data are significantly smaller $(r=0.61)$. Possible reasons are the influence of not measured precursors, for example isoprene, and the inapplicability of a quasi steady state model under the spatially inhomogeneous conditions in Jülich. Again the model overpredicts the $\mathrm{OH}$ concentration by about $15 \%$, which is somewhat smaller than for the rural case.

The precision of the comparison is limited by the uncertainties of the chemical reaction rate constants. 



\section{Contents}

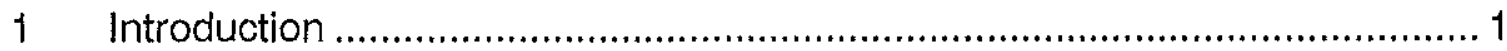

2 A reduced reaction scheme of the atmospheric $\mathrm{OH}$ chemistry .................... 2

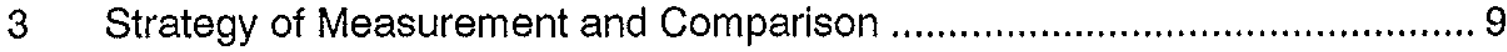

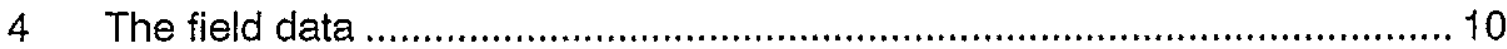

5 The Chemical Reaction Scheme ................................................... 12

6 Comparison of Measurements with Calculated $\mathrm{OH}$ Concentrations ............ 14

6.1 The Campaigns in Rural Environments ....................................... 14

6.2 The Campaigns under Moderately Polluted Conditions...................... 18

6.3 Error Analysis of the Comparison ............................................. 22

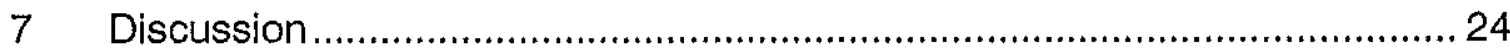

7.1 Sensitivity Studies.......................................................... 24

7.2 Correlations with Precursors.................................................. 26

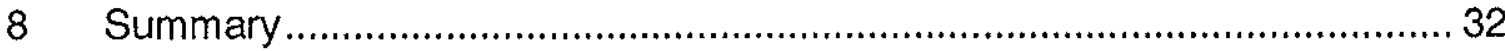

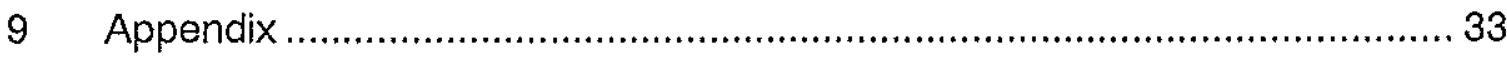

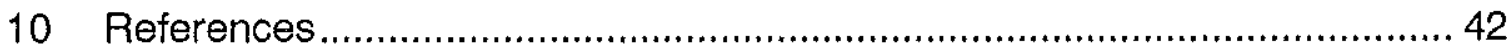





\section{Introduction}

Experimental and model work have provided increasing evidence that the hydroxyl radical $\mathrm{OH}$ is the most important oxidizing reagent in the lower atmosphere during daytime (Levy, 1971 and 1972, Ehhalt et al., 1991). It is produced by the photolysis of ozone at wavelengths below $320 \mathrm{~nm}$

$$
\mathrm{O}_{3}+\mathrm{hv} \quad \rightarrow \quad \mathrm{O}\left({ }^{1} \mathrm{D}\right)+\mathrm{O}_{2}
$$

generating electronically excited oxygen atoms, $O\left({ }^{4} D\right)$. Their excitation energy (ca. $2 \mathrm{eV}$ ) opens a reaction channel with water vapor molecules to form $\mathrm{OH}$ radicals

$$
\mathrm{O}\left({ }^{4} \mathrm{D}\right)+\mathrm{H}_{2} \mathrm{O} \quad \rightarrow \quad 2 \mathrm{OH}
$$

The hydroxyl radical reacts with most atmospheric trace gases initiating their oxidation and eventual removal from the troposphere through subsequent chemical processes. For many compounds the rate determining step of this degradation is the reaction with $\mathrm{OH}$ so that their tropospheric life time is determined by the concentration of $\mathrm{OH}$. As a consequence, changes of the $\mathrm{OH}$ concentration would result in corresponding changes of the atmospheric trace gas concentration. In addition, the net chemical production of ozone in the presence of sufficient $\mathrm{NO}_{x}$ depends nearly linearly on the destruction rate of $\mathrm{CO}, \mathrm{CH}_{4}$ and other non-methane-hydrocarbons $(\mathrm{NMHC})$ by $\mathrm{OH}$, which again underlines the importance of $\mathrm{OH}$. Chemical models based on laboratory kinetic studies and atmospheric observations have provided insight into the couplings of the chemical system in the atmosphere (Logan et al., 1981, Weinstock et al., 1980, Ehhalt, 1986, 1987, and 1991, Liu et al., 1987, Thompson et al., 1990, Poppe et al., 1992, 1993a) and have identified the chemical processes and meteorological parameters which control the $\mathrm{OH}$ abundance. It could be shown that the chemistry of $\mathrm{OH}$ is to a varying degree coupled to all trace gases, in particular to the nitrogen oxides, ozone, and the hydrocarbons. 
The ultimate test of the applicability of such models and their validity for the atmosphere is a comparison of model calculations with measured tropospheric $\mathrm{OH}$ concentrations. Here we will analyze local measurements of $\mathrm{OH}$ performed in near surface air during summer periods in rural and moderately polluted environments in Germany.

Such a comparison is simplified by the fact that $\mathrm{OH}$ and the peroxy radicals have short lifetimes due to their high reactivity. Transport of short lived compounds does not contribute significantly to their local concentrations so that a zerodimensional model with no spatial resolution suffices to describe the fast chemical processes. Quasi-steady-state concentrations are attained within minutes and the $\mathrm{OH}$-concentration is solely determined by the concentrations of longer-lived reactands and meteorological parameters. These support data have to be measured simultaneously in order to make a comparison of experimental and model $\mathrm{OH}$ data meaningful. At this stage only those processes need to be addressed which dominantly influence the $\mathrm{OH}$ concentration.

\section{A reduced reaction scheme of the atmospheric $\mathrm{OH}$ chemistry}

It is one of the characteristic features of the atmospheric $\mathrm{OH}$ chemistry (see for example Atkinson et al., 1989), that although $\mathrm{OH}$ is involved in many reactions as reactand and product the chemistry follows a simple picture. It consists of the production of radicals in reactions initiated by photolysis of long lived precursors, the destruction under formation of compounds which provide negligible feedback to the $\mathrm{OH}$ chemistry, and oxidation reactions associated with rapid cycling between $\mathrm{OH}$ and various peroxy radicals. Here we summarize the most important reactions of $\mathrm{OH}$. As mentioned before it is primarily produced in a two-stepmechanism starting with the photolysis (R1) of $\mathrm{O}_{3}$ which leads to electronically excited oxygen atoms, $\mathrm{O}\left({ }^{1} \mathrm{D}\right)$. They are partly quenched to $\mathrm{O}\left({ }^{3} \mathrm{P}\right)$

$$
\mathrm{O}\left({ }^{1} \mathrm{D}\right)+\mathrm{O}_{2} \quad \rightarrow \quad \mathrm{O}\left({ }^{3} \mathrm{P}\right)+\mathrm{O}_{2}
$$




$$
\mathrm{O}\left({ }^{1} \mathrm{D}\right)+\mathrm{N}_{2} \quad \rightarrow \quad \mathrm{O}\left({ }^{3} \mathrm{P}\right)+\mathrm{N}_{2}
$$

In reactions with gaseous water molecules (R2), however, two $\mathrm{OH}$ radicals emerge. Reactions $\mathrm{R} 1-\mathrm{R} 3$ establish an effective $\mathrm{OH}$ source with the production rate $P_{O H}$ under steady state assumptions for $O(' D)$

$$
P_{\mathrm{OH}}=\mathrm{gJ}_{1}\left[\mathrm{O}_{3}\right]
$$

with the branching ratio $\mathrm{g}$

$$
g=\frac{2 k_{2}\left[\mathrm{H}_{2} \mathrm{O}\right]}{\mathrm{k}_{3 \mathrm{a}}\left[\mathrm{O}_{2}\right]+\mathrm{k}_{3 \mathrm{~b}}\left[\mathrm{~N}_{2}\right]+\mathrm{k}_{2}\left[\mathrm{H}_{2} \mathrm{O}\right]}
$$

Photolysis rates are denoted by $\mathrm{J}$, while reaction constants are abbreviated by $\mathrm{k}$. There are two generically different destruction paths. In the first one the hydroxyl radical is depleted under formation of products (in one or more steps) which are all long-lived and have only a very small impact on the $\mathrm{OH}$ chemistry. On the time scale of $\mathrm{OH}$ these reactions practically constitute ultimate sinks for radicals. For $\mathrm{NO}_{2}$ concentrations above $1 \mathrm{ppb}$ the most important reaction of this type is the production of $\mathrm{HNO}_{3}$ in the three body reaction

$$
\mathrm{NO}_{2}+\mathrm{OH}+\text { air } \quad \rightarrow \quad \mathrm{HNO}_{3}+\text { air }
$$

The second pathway is the degradation of $\mathrm{OH}$ in reactions leading to other short lived compounds whose subsequent reactions recyle $\mathrm{OH}$. The reactions with $\mathrm{CO}$, $\mathrm{CH}_{4}$, almost all hydrocarbons, and partly oxidized compounds like the aldehydes belong to this category. In the case of $\mathrm{CO}$ another important radical $\mathrm{HO}_{2}$ is generated:

$$
\begin{array}{lll}
\mathrm{CO}+\mathrm{OH} & \rightarrow & \mathrm{CO}_{2}+\mathrm{H} \\
\mathrm{H}+\mathrm{O}_{2}+\text { air } & \rightarrow & \mathrm{HO}_{2}+\text { air }
\end{array}
$$

The hydrogen peroxy radical oxidizes $\mathrm{NO}$ to $\mathrm{NO}_{2}$

$$
\mathrm{HO}_{2}+\mathrm{NO} \quad \rightarrow \quad \mathrm{OH}+\mathrm{NO}_{2}
$$


or reacts with ozone

$$
\mathrm{HO}_{2}+\mathrm{O}_{3} \quad \rightarrow \quad \mathrm{OH}+2 \mathrm{O}_{2}
$$

The reaction with ozone contributes only significantly to the radical recycling if $\mathrm{NO}_{x}$ is low. In both cases $\mathrm{OH}$ is regenerated. The regeneration of $\mathrm{OH}$ competes with losses from peroxy radical-peroxy radical-reactions which are generically described by

$$
\mathrm{HO}_{2}+\mathrm{HO}_{2} \rightarrow \mathrm{H}_{2} \mathrm{O}_{2}+\mathrm{O}_{2}
$$

where the long lived hydrogen peroxide is formed. Obviously the net loss of $\mathrm{OH}$ depends on the branching between reactions R6 and R7 and reaction R8. A similar reaction scheme applies to the oxidation of the hydrocarbons consisting of the initial attack by $\mathrm{OH}$ and radical recycling in one or more steps.

Important to the radical budget is also the photolysis of formaldehyde

$$
\mathrm{HCHO}+\mathrm{hv} \quad \rightarrow \quad \mathrm{H}+\mathrm{HCO}
$$

followed by R5a and

$$
\mathrm{HCO}+\mathrm{O}_{2} \rightarrow \mathrm{CO}+\mathrm{HO}_{2}
$$

resulting in a $\mathrm{HO}_{2}$-production

$$
\mathrm{P}_{\mathrm{HO}_{2}}=2 \mathrm{~J}_{9}[\mathrm{HCHO}]
$$

Formaldehyde is also oxidized by $\mathrm{OH}$

$$
\mathrm{OH}+\mathrm{HCHO} \rightarrow \mathrm{HCO}+\mathrm{H}_{2} \mathrm{O}
$$

with radical recycling in $\mathrm{R} 9 \mathrm{a}$.

Another generic feature of the $\mathrm{OH}$ chemistry is the coupling to radical reservoirs, the most important being peroxyacetyl nitrate (PAN). The effectiveness of the reservoir depends on the abundance of acetaldehyde, which is formed during the oxidation of several NMHC. The first step is the reaction of $\mathrm{OH}$ with acetaldehyde 


$$
\mathrm{CH}_{3} \mathrm{CHO}+\mathrm{OH} \rightarrow \mathrm{CH}_{3} \mathrm{CO}+\mathrm{H}_{2} \mathrm{O}
$$

followed by a rapid three body reaction of the acetyl radical

$$
\mathrm{CH}_{3} \mathrm{CO}+\mathrm{O}_{2}+\text { air } \rightarrow \mathrm{CH}_{3} \mathrm{COO}_{2}+\text { air }
$$

There are two main depletion reactions for $\mathrm{CH}_{3} \mathrm{COO}_{2}$. Firstly, the recycling to $\mathrm{HO}_{2}$ given by reaction R12 which summarizes the elementary steps R12 (a-e):

$$
\begin{array}{lll}
\mathrm{CH}_{3} \mathrm{COO}_{2}+\mathrm{NO} & \rightarrow & \mathrm{CH}_{3} \mathrm{COO}+\mathrm{NO}_{2} \\
\mathrm{CH}_{3} \mathrm{COO} & \rightarrow & \mathrm{CH}_{3}+\mathrm{CO}_{2} \\
\mathrm{CH}_{3}+\mathrm{O}_{2}+\text { air } & \rightarrow & \mathrm{CH}_{3} \mathrm{O}_{2}+\text { air } \\
\mathrm{CH}_{3} \mathrm{O}_{2}+\mathrm{NO} & \rightarrow & \mathrm{CH}_{3} \mathrm{O}+\mathrm{NO}_{2} \\
\mathrm{CH}_{3} \mathrm{O}+\mathrm{O}_{2} & \rightarrow & \mathrm{HCHO}+\mathrm{HO}_{2} \\
& & \\
\mathrm{CH}_{3} \mathrm{COO}_{2}+2 \mathrm{NO} & \rightarrow & \mathrm{HO}_{2}+2 \mathrm{NO}_{2}
\end{array}
$$

Recyling is completed by subsequent formation of $\mathrm{OH}$ in R6 and R7. Secondly, PAN is produced

$$
\mathrm{CH}_{3} \mathrm{COO}_{2}+\mathrm{NO}_{2}+\mathrm{air} \rightarrow \quad \mathrm{PAN}+\text { air }
$$

The reverse reaction to $\mathrm{R} 13$ is the strongly temperature dependent thermal decomposition of PAN

$$
\mathrm{PAN}+\text { air } \quad \rightarrow \quad \mathrm{CH}_{3} \mathrm{COO}_{2}+\mathrm{NO}_{2}+\text { air }
$$

Net formation of PAN introduces a net radical loss of the same magnitude (Poppe et al., 1993a). As already discussed (Cox, 1977) the effective kinetics of PAN under steady-state-conditions for the acetyl- and the acetylperoxy radical is given by

$$
\frac{\mathrm{d}[\mathrm{PAN}]}{\mathrm{dt}}=\mathrm{bk}_{11}[\mathrm{OH}]\left[\mathrm{CH}_{3} \mathrm{CHO}\right]-(1-\mathrm{b}) \mathrm{k}_{14}[\mathrm{PAN}]
$$


where $\mathrm{b}$ is determined by the branching between $\mathrm{R} 12$ and $\mathrm{R} 13$

$$
b=\frac{1}{1+\frac{k_{12}[\mathrm{NO}]}{k_{13}\left[\mathrm{NO}_{2}\right]}}
$$

The influence of PAN on the radical budget depends on temperature and on the partitioning of $\mathrm{NO}_{x}$ in $\mathrm{NO}$ and $\mathrm{NO}_{2}$. Invoking photostationarity for $\mathrm{NO}_{2}$ and $\mathrm{NO}$ which is derived from

$$
\begin{array}{lll}
\mathrm{NO}_{2}+\mathrm{hv} & \rightarrow & \mathrm{NO}+\mathrm{O}\left({ }^{3} \mathrm{P}\right) \\
\mathrm{O}\left({ }^{3} \mathrm{P}\right)+\mathrm{O}_{2}+\text { air } & \rightarrow & \mathrm{O}_{3}+\text { air } \\
\mathrm{O}_{3}+\mathrm{NO} & \rightarrow & \mathrm{NO}_{2}+\mathrm{O}_{2}
\end{array}
$$

one obtains

$$
\frac{[\mathrm{NO}]}{\left[\mathrm{NO}_{2}\right]}=\frac{\mathrm{J}_{15}}{\mathrm{k}_{16}\left[\mathrm{O}_{3}\right]+\mathrm{k}_{6}\left[\mathrm{HO}_{2}\right]}
$$

Depending on $J_{15}$ and the ozone level NO reaches its steady state typically within minutes.

These sixteen reactions contain the generic chemical paths of the $\mathrm{OH}$ chemistry. The peroxy radical and the nitrogen oxide chemistry are coupled by $R 6$, however, $\mathrm{OH}$ is much more sensitive to NO than vice versa. Under steady-state assumptions for $\mathrm{OH}, \mathrm{HO}_{2}$, and $\mathrm{CH}_{3} \mathrm{CO}_{3}$ the corresponding kinetic equations give the corresponding concentrations:

$$
\begin{aligned}
\frac{\mathrm{d}[\mathrm{OH}]}{\mathrm{dt}} & =\mathrm{P}_{\mathrm{OH}}+\mathrm{k}_{6}[\mathrm{NO}]\left[\mathrm{HO}_{2}\right]+\mathrm{k}_{7}\left[\mathrm{O}_{3}\right]\left[\mathrm{HO}_{2}\right] \\
& -\left(\mathrm{k}_{4}\left[\mathrm{NO}_{2}\right]+\mathrm{k}_{5}[\mathrm{CO}]+\mathrm{k}_{10}[\mathrm{HCHO}]+\mathrm{k}_{11}\left[\mathrm{CH}_{3} \mathrm{CHO}\right]\right)[\mathrm{OH}]
\end{aligned}
$$

The budget for the sum of radical concentrations [RAD] $\left(=[\mathrm{OH}]+\left[\mathrm{HO}_{2}\right]+\left[\mathrm{CH}_{3} \mathrm{CO}_{3}\right]\right)$ reads 


$$
\frac{\mathrm{d}[\mathrm{RAD}]}{\mathrm{dt}}=\mathrm{P}-\frac{\mathrm{d}[\mathrm{PAN}]}{\mathrm{dt}}-\mathrm{k}_{4}[\mathrm{OH}]\left[\mathrm{NO}_{2}\right]-2 \mathrm{k}_{8}\left[\mathrm{HO}_{2}\right]^{2}
$$

with $d[P A N] / d t$ from eq(2) and

$$
P=P_{\mathrm{OH}}+P_{\mathrm{HO}_{2}}
$$

Combining eqs(4) and (5) one deduces the steady-state concentration of $\mathrm{OH}$ from a quadratic equation

$$
[\mathrm{OH}]=-\mathrm{A}+\sqrt{\mathrm{A}^{2}+\mathrm{B}}
$$

with abbreviations

$$
\begin{aligned}
& c=\frac{k_{4}\left[\mathrm{NO}_{2}\right]+k_{5}[\mathrm{CO}]+k_{10}[\mathrm{HCHO}]+k_{11}\left[\mathrm{CH}_{3} \mathrm{CHO}\right]}{k_{6}[\mathrm{NO}]+k_{7}\left[\mathrm{O}_{3}\right]} \\
& d=\frac{\mathrm{POH}_{\mathrm{OH}}}{k_{4}\left[\mathrm{NO}_{2}\right]+\mathrm{k}_{5}[\mathrm{CO}]+\mathrm{k}_{10}[\mathrm{HCHO}]+\mathrm{k}_{11}\left[\mathrm{CH}_{3} \mathrm{CHO}\right]} \\
& A=\frac{b \mathrm{k}_{11}\left[\mathrm{CH}_{3} \mathrm{CHO}\right]+\mathrm{k}_{4}\left[\mathrm{NO}_{2}\right]}{4 \mathrm{k}_{8} \mathrm{C}^{2}}-\mathrm{d} \\
& B=P+\frac{(1-b) \mathrm{k}_{14}[\mathrm{PAN}]}{2 \mathrm{k}_{8} \mathrm{c}^{2}}-\mathrm{d}^{2}
\end{aligned}
$$

The term $\mathrm{d}$ can be interpreted as an $\mathrm{OH}$ concentration in the absence of the recycling of radicals in $R 6$ and $R 7$. Therefore $d$ is usually much smaller than the actual $[\mathrm{OH}]$.

Limiting cases elucidate the generic features of the $\mathrm{OH}$-level as function of the chemical environment.

$\mathrm{NO}_{2}$-concentrations $\gg 1 \mathrm{ppb}$ imply 


$$
A^{2} \gg B
$$

Expanding the root to first order and neglecting $d$ leads to a simplified expression for $[\mathrm{OH}]$ :

$$
[\mathrm{OH}]=\frac{\mathrm{P}+(1-\mathrm{b}) \mathrm{k}_{14}[\mathrm{PAN}]}{\mathrm{k}_{4}\left[\mathrm{NO}_{2}\right]+\mathrm{bk}_{11}\left[\mathrm{CH}_{3} \mathrm{CHO}\right]}
$$

Under these conditions the dependence on $\mathrm{k}_{8}$ vanishes which means that the loss via $R 8$ is negligibly small compared to destruction in $\mathrm{R} 4$. The $\mathrm{OH}$-concentration depends linearly on ozone and formaldehyde via the primary production P. Going beyond the reduced mechanism $\mathrm{P}$ can be generalized to the overall radical production term from long-lived precursors. The destruction is basically proportional to $\left[\mathrm{NO}_{2}\right]$ via $\mathrm{R} 4$ which is the dominant loss of radicals under a high $\mathrm{NO}_{x}$ level. High $\mathrm{NO}_{x}$ concentrations also implies that the radical recycling is complete making $[\mathrm{OH}]$ independent of [CO]. Modification of this simple picture are caused by the PAN chemistry which adds a further influence of ozone and the $\mathrm{NO}_{2}$ photolysis rate. The direct influence of the PAN-budget on the $\mathrm{OH}$-abundance can be seen even more clearly from an equivalent form of eq(7a)

$$
[\mathrm{OH}]=\frac{\mathrm{P}-\frac{\mathrm{d}[\mathrm{PAN}]}{\mathrm{dt}}}{\mathrm{k}_{4}\left[\mathrm{NO}_{2}\right]}
$$

where $\mathrm{d}[\mathrm{PAN}] / \mathrm{dt}$ is the net chemical production of PAN (see eq(2)). Depending on the sign the PAN-chemistry acts as a radical source or sink.

For low $\mathrm{NO}_{\mathrm{X}}$ levels $<<0.1 \mathrm{ppb}$ reaction $\mathrm{R} 4$ is not longer important. Keeping only leading terms in eqs $(4,5)$ one deduces then

$$
\left[\mathrm{HO}_{2}\right]=\sqrt{\frac{P-\frac{d[\mathrm{PAN}]}{d t}}{2 \mathrm{k}_{8}}}
$$

and 


$$
[\mathrm{OH}]=\frac{\mathrm{P}_{\mathrm{OH}}+\left(\mathrm{k}_{6}[\mathrm{NO}]+\mathrm{k}_{7}\left[\mathrm{O}_{3}\right]\right)\left[\mathrm{HO}_{2}\right]}{\mathrm{k}_{5}[\mathrm{CO}]+\mathrm{k}_{10}[\mathrm{HCHO}]+\mathrm{k}_{11}\left[\mathrm{CH}_{3} \mathrm{CHO}\right]}
$$

Contrary to the $\mathrm{NO}_{x}$-rich case the $\mathrm{OH}$ concentration is increasing with the $\mathrm{NO}_{x}$ level. The dependence on ozone is stronger than linear. A net $\mathrm{OH}$-destruction proportional to [CO] indicates the low recycling efficiency of radicals and the effective radical depletion by the self reaction (R8) of $\mathrm{HO}_{2}$.

For medium $\mathrm{NO}_{x}$ one expects a general damping of all dependencies because of the square-root in eq(6) and competing influences of $\mathrm{NO}$ and $\mathrm{NO}_{2}$ expressed in $\mathrm{A}$ and $B$.

\section{Strategy of Measurement and Comparison}

The chemistry of $\mathrm{OH}$ and the associated peroxy radicals dictate the strategy for a meaningful comparison of calculated and modeled $\mathrm{OH}$ concentrations. The kinetics of the radicals are strongly coupled and box model calculations show that the time $\mathrm{T}$ needed to reach stationarity for $\mathrm{OH}$, the peroxy radicals, and photostationarity for $\mathrm{NO}$ and $\mathrm{NO}_{2}$ is of the order of one minute. Since the integration time of the $\mathrm{OH}$ measurement was much larger than $\mathrm{T}$ and varied between 10 minutes and several hours, the experiments could not resolve transient effects in the local concentrations. Therefore stationarity of the radical concentrations is assumed for the comparison with the model. Consequently the experimental site should display horizontal uniformity so that air parcels passing the site have experienced constant chemical and meteorological conditions for at least $T$ to attain quasi steady state concentrations. For example with a wind speed of $5 \mathrm{~m} / \mathrm{s}$ and $T=1 \mathrm{~min}$ this requirement implies horizontal homogeneity over at least $300 \mathrm{~m}$. Vertical transport and dry deposition influence the local $\mathrm{OH}$ budget in two ways. Firstly, the highly reactive $\mathrm{OH}$ and peroxy radicals are expected to be effectively deposited at the surface. Secondly, the gradients of the chemical precursors induce additional fluxes of $\mathrm{OH}$. Thus the local chemical budget of $\mathrm{OH}$ a few meters above ground can be considerably perturbed by transport. Due to the 
high variability of these fluxes it is very difficult to model quantitatively the influence on $\mathrm{OH}$. Therefore measurements should also take place well off the ground. The experimental data of $\mathrm{OH}$ must be accompanied by measurements of the longer lived precursors and meteorological parameters in the same mass of air. Then a zero dimensional transport independent model is adequate for the comparison.

\section{The field data}

There are only very few data sets available for an intercomparison of modeled and calculated $\mathrm{OH}$ concentrations since the direct detection of atmospheric $\mathrm{OH}$ is very difficult. Overviews of the experimental techniques and the existing data of measured atmospheric $\mathrm{OH}$ concentrations are given by Altshuller (1989) and Hewitt and Harrison (1985). The Institute of Atmospheric Chemistry in Jülich is one of the groups that have performed simultaneous measurements of $\mathrm{OH}$ and the necessary support data to characterize the air mass containing $\mathrm{OH}$. With respect to the applied measurement techniques for $\mathrm{OH}$ and other trace gases the reader is refered to Perner et al. (1987), Platt et al. (1987 and 1988), Dorn et al. (1988), Callies (1988), Junkermann et al. (1989), and Hofzumahaus et al. (1991). Recently Mount (1992) and Comes (1992) performed $\mathrm{OH}$ measurements in rural air utilizing similar techniques. Felton (1988) and Felton et al. (1988 and 1991) conducted campaigns utilizing an in-situ ${ }^{14} \mathrm{C}$-method for $\mathrm{OH}$. They measured only a small set of support data which makes the comparison with model calculations rather uncertain. Eisele et al. (1991) determined [OH] by mass spectrometry, however, no support data were reported.

Our field data were obtained at three different locations in Germany. All campaigns were conducted during summertime in meteorologically stable conditions with bright sunshine. Moreover, the visibility was always good as it is required by the applied long-path-absorption-technique for $\mathrm{OH}$.

The 1983 campaign took place in Deuselbach at a rural station at $480 \mathrm{~m}$ altitude (Perner et al., 1987) with negligible pollutant sources nearby. The long path 
absorption technique probed air in $55 \mathrm{~m}$ above ground on the average.

The field experiment in 1984 was conducted at Schauinsland, a mountain station about $1300 \mathrm{~m}$ above sea level in the Black Forest. Due to its altitude, the station experiences very different air masses during the day since the site is above the planetary boundary layer (PBL) in the morning hours while in the early afternoon it is within the PBL because of the increased height of the mixing layer. The $\mathrm{OH}$ data were taken in $200 \mathrm{~m}$ height above ground on the average. Both stations exhibited relatively low nitrogen oxides and NMHC concentrations during the campaigns. For example, $\left[\mathrm{NO}_{2}\right]$ varies between $0.4 \mathrm{ppb}$ and $2 \mathrm{ppb}$, while ethene abundances were between $0.3 \mathrm{ppb}$ and $1 \mathrm{ppb}$.

The campaigns in 1987 and 1988 were located in Jülich at $100 \mathrm{~m}$ altitude. Jülich is a rural site with some small paper mills and chemical factories. It is surrounded by nearby sources of trace gases from automobile exhaust and small chemical research facilities. The area exhibits rather high $\mathrm{NMHC}$ and $\mathrm{NO}_{2}$ concentrations, the latter varying between $2 \mathrm{ppb}$ and more than $10 \mathrm{ppb}$ during both field experiments. $\mathrm{OH}$ concentrations were probed in $60 \mathrm{~m}$ height above the surface.

During both types of campaigns most of the important inorganic precursors of $\mathrm{OH}$ like $\mathrm{NO}_{2}, \mathrm{O}_{3}, \mathrm{H}_{2} \mathrm{O}$, and the photolysis frequencies of $\mathrm{O}_{3}$ and $\mathrm{NO}_{2}$ were monitored continuously.

The measured set of organic compounds and the measurement frequencies, however, were very different for the campaigns. For example, in 1983 and 1984 many NMHC, even the reactive species, were measured only once or twice per day and PAN measurements were not done at all. Also often the data do not refer to the same time with the same interval of integration. Sometimes the time elapsed between the $\mathrm{OH}$ and the precursor measurements exceeds several hours. Then the data were completed in particular for acetaldehyde, propane, and CO during the early campaigns in 1983/84 and also for the Jülich data of 1987 . The completion was based on the experimental data of the 1988 campaign (Poppe et al.,1993b) when the hydrocarbons and all other parameters were measured on a regular basis several times per day. The anthropogenic hydrocarbons, $\mathrm{CO}$, and $\mathrm{NO}_{x}$ are positively correlated with correlation coefficients, $r$, larger than 0.7 with typical values of 0.8 . A linear regression analysis (Wallasch et al., 1994) allows to estimate missing precursor concentrations. 
Even after completion the data sets are inhomogeneous with respect to the set of measured organic compounds. A possible influence of this inhomogeneity on the calculated $\mathrm{OH}$ concentrations should be excluded in order to make the campaigns intercomparable. Therefore only a common subset of precursors were selected for the desired comparison which were measured during all campaigns. These experimental data were compiled in table 1.

\section{The Chemical Reaction Scheme}

The impact of chemical precursors and other parameters is taken into account in calculations that model the budget of $\mathrm{OH}$ under the influence of chemical losses and production processes. The gas phase chemistry of the Regional Acid Deposition Model (RADM2) was chosen to model the $\mathrm{OH}$ concentration. The chemical scheme contains an explicit organic chemistry for hydrocarbons up to $\mathrm{C}_{2}$ and treats all higher NMHC in a lumped fashion (Stockwell et al., 1990, Middleton et al., 1990). It was designed primarily for rural but also polluted environments and is therefore applicable to all campaigns. The comparison of the RADM2 with several other recent reaction schemes by Hough (1988) and Dodge (1989) showed quantitative agreement for $\mathrm{OH}$ and various other short-lived compounds among the different formulations of the chemistry despite the considerable differences in the implementations of the organic reactions.

Input for the model are the experimental data for the long-lived precursors and the photolysis frequencies. Obviously the model requires more parameters to be specified than are available from the measurements.

The missing data fall into three categories. Firstly, those that are known from model calculations to be of little influence on $\mathrm{OH}$, so that their actual values are not crucial. The photolysis of organic peroxides and $\mathrm{H}_{2} \mathrm{O}_{2}$ produces $\mathrm{OH}$ and peroxy radicals. However, their mixing ratios are not likely to exceed several ppb so that their contribution is still small compared to the production from R1-R2. Degradation products of the hydrocarbons for example, which react very slowly or not at all with either $\mathrm{OH}$ or the peroxy radicals, belong also to this category. 
Secondly, glyoxal, methylglyoxal, dicarbonyls, and ketones, which are produced during the oxidation of several higher $\mathrm{NMHC}$, react quickly with $\mathrm{OH}$ and are therefore potentially important. Higher NMHC belong to this group, too. For the comparison presented here the influence of these compounds was neglected by assigning vanishing concentrations (see sec. 7). Thirdly, those that are known to be important for $\mathrm{OH}$. The photolysis frequencies of formaldehyde and acetaldehyde fall into this group. Their J-values are calculated from the experimental ozone photolysis frequency by scaling with the calculated photolysis data from a photon flux model (Röth, 1994).

As already mentioned in section 4 only a subset of NMHC was taken as measured to treat all campaigns on the same basis. All others were included by relating their mixing ratios to those of propane, ozone, and $\mathrm{NO}_{2}$ used as leading factors. They were taken from an analysis of the corresponding correlations deduced from the comprehensive hydrocarbon data base of the Jülich campaign in 1988 (M. Wallasch et al., 1994). The diurnal cycles of several hydrocarbons (methane, ethane, propane, n-butane, i-butane, n-pentane, i-pentane, ethene, propene, 1-butene, ethine, benzene, toluene, o-xylene, $p / m-x y l e n e)$ were measured. The relations are entered into table 2 together with an estimated error. As indicated the relations were slightly modified for the Deuselbach campaign (1983) to meet the observation of relatively high alkene mixing ratios during that period. For PAN the correlation was taken with the exception of 1988, when measured PAN concentration were available. Also in this case a sensitivity study has to demonstrate the impact of this approximation on $\mathrm{OH}$.

Unfortunately there are no experimental data available on fast reacting biogenic hydrocarbons, in particular isoprene and its degradation products methyl vinyl ketone and methacrolein. The concentrations of the short-lived compounds are calculated in the steady-state approximation using these data as input. Short-lived species are oxygen atoms, $\mathrm{OH}, \mathrm{HO}_{2}$ and all peroxy radicals associated with the oxidation of hydrocarbons. The nitrogen compounds $\mathrm{HONO}, \mathrm{NO}_{3}, \mathrm{~N}_{2} \mathrm{O}_{5}, \mathrm{HNO}_{4}$, and also NO are treated as steady-state species using the full chemical scheme of RADM2, that includes in particular the NO-losses due to reactions with the peroxy radicals. All other species included in the scheme are fixed parameters as specified from the experiments. 


\section{Comparison of Measurements with Calculated $\mathrm{OH}$ Concentrations}

\subsection{The Campaigns in Rural Environments}

The earlier campaigns in Deuselbach (1983) and at Schauinsland (1984) are the simpler case. From reactions $\mathrm{R} 1$ and $\mathrm{R} 2$ one would predict a dependence of $[\mathrm{OH}]$ on the photolysis of ozone. Indeed, the diurnal cycle of the measured $\mathrm{OH}$ concentration and the photolysis rate (figure 1) vary in parallel.

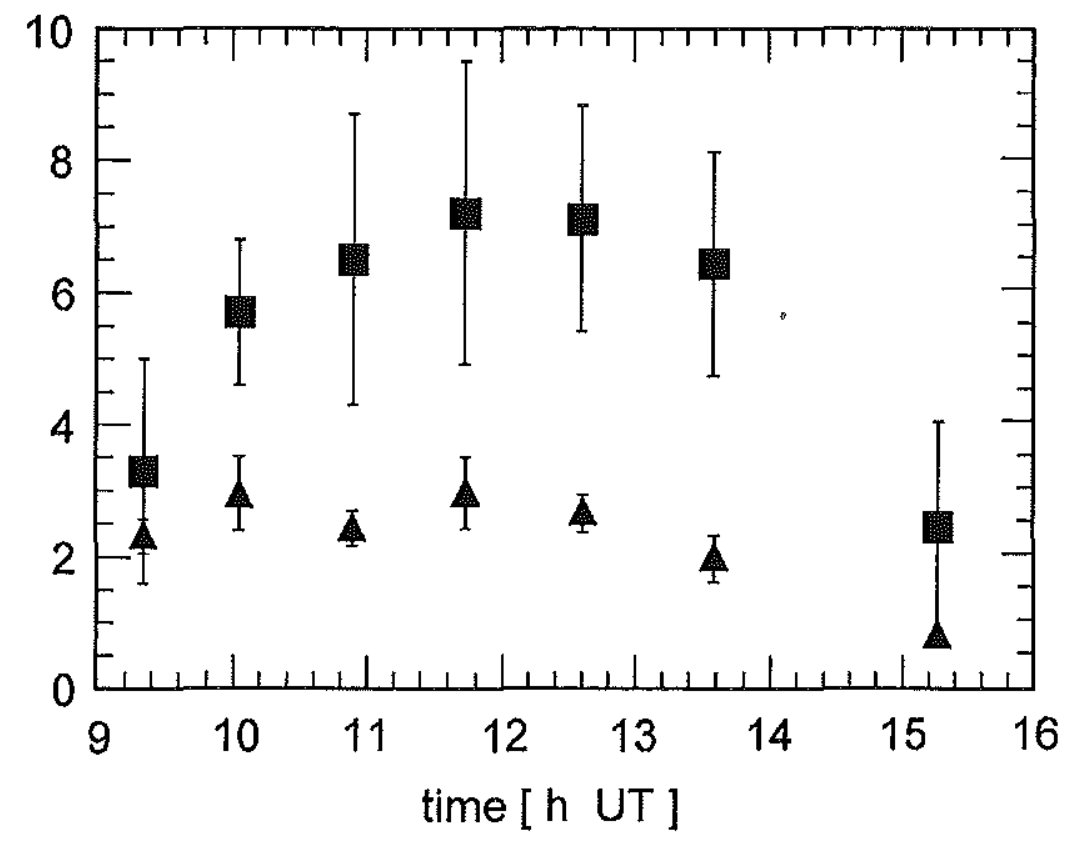

Fig. 1: Diurnal variation of the measured $\mathrm{OH}$ concentration (squares) in units of $10^{6} \mathrm{~cm}^{-3}$ and the photolysis frequency of ozone (triangles) in units of $10^{5} \mathrm{~s}^{-1}$ at Schauinsland, June 25, 1984.

This relation is shown more clearly and quantitatively in figure 2, where the measured $\mathrm{OH}$ data at Deuselbach and Schauinsland are plotted against the photolysis rate of reaction $\mathrm{R} 1$ denoted by $J_{i}$. 


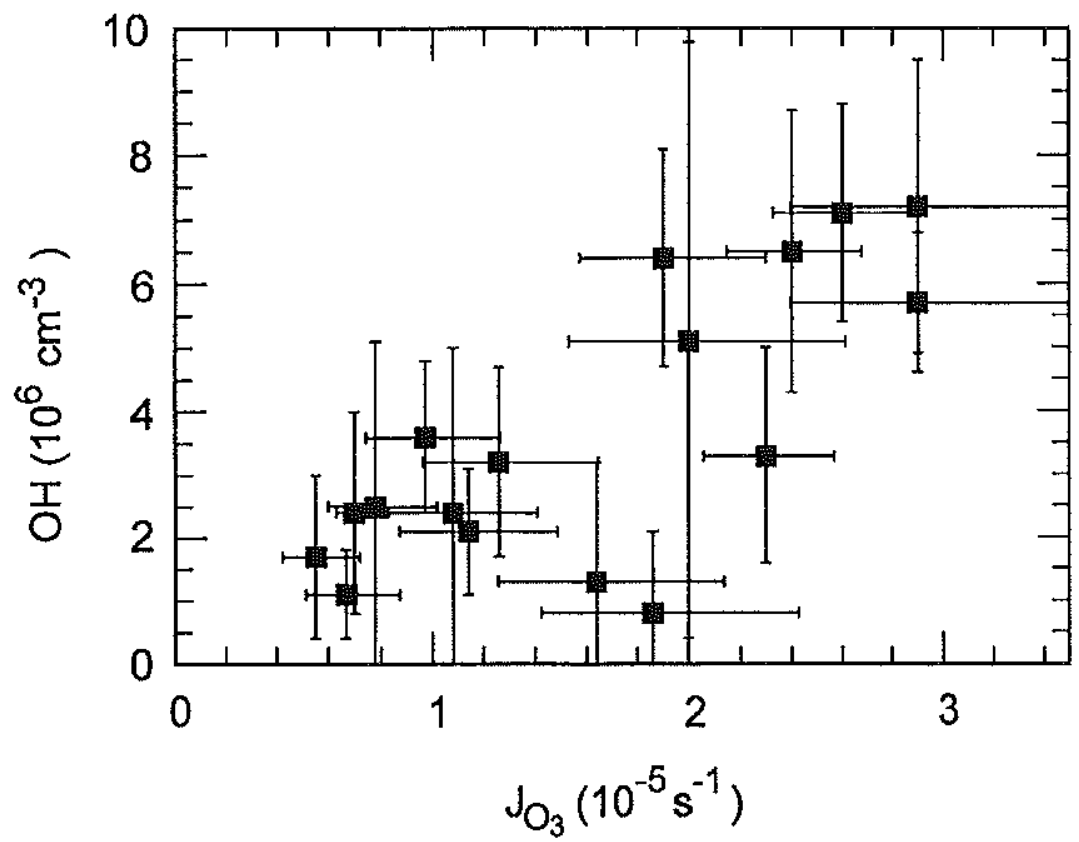

Fig. 2: $\quad$ Correlation of measured $\mathrm{OH}$-concentrations with simultaneously observed frequencies of the photolysis of ozone from the Deuselbach (1983) and Schauinsland (1984) campaign. Error bars indicate the mean standard deviation. The correlation coefficient is 0.76 .

The correlation coefficient, $\mathrm{r}\left(\mathrm{OH}, \mathrm{J}_{1}\right)$, is 0.76 with a $95 \%$-confidence interval of $0.43 \ldots 0.91 . r^{2}\left(O H, J_{1}\right)=0.58$ is the fraction of the total variance of $[O H]$ that can be explained by a linear dependence on $J_{i}$. The remaining variance stems from the experimental uncertainty of $\mathrm{OH}$ and $\mathrm{J}_{1}$ and from the influence of other precursors and parameters on which the $\mathrm{OH}$-concentration depends. Indeed, the model predicts a much larger correlation between the calculated $\mathrm{OH}$ (denoted by subscript $\mathrm{C}$ ) and the measured ozone photolysis frequency with $\mathrm{r}\left(\mathrm{OH}_{\mathrm{C}}, \mathrm{J}_{1}\right)=0.90$. Measured and calculated $\mathrm{OH}$-concentrations are compared in figure 3 . The error bars of the experimental data display the 1- $\sigma$ error of an individual measurement. Systematic errors for example from the uncertainty of the $\mathrm{OH}$ absorption cross section are not taken into account. 


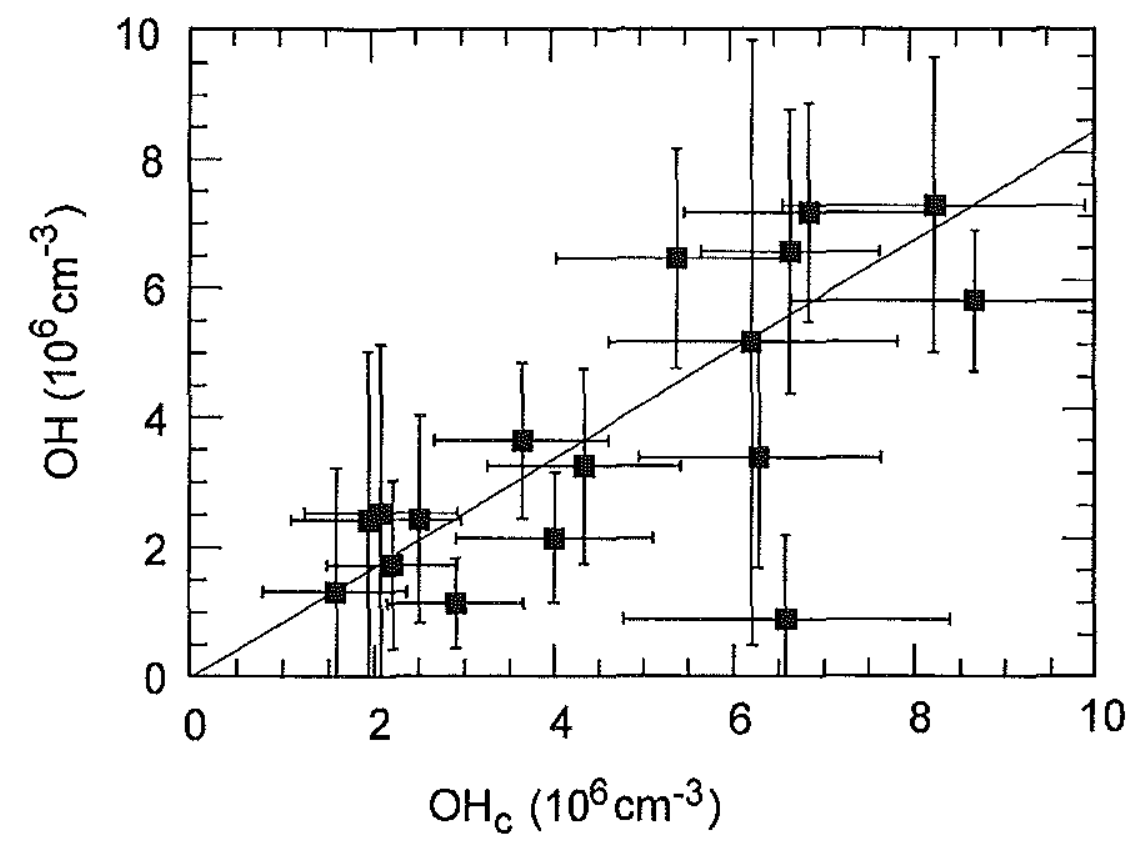

Fig. 3: Correlation of measured and calculated $\mathrm{OH}$ concentrations at Schauinsland and Deuselbach. The error bars represent the mean standard deviations, the straight line is calculated from a least squares fit through the data and the origin. (Correlation coefficient $=0.73$ )

Each individual precursor has uncertainties from two sources. Firstly, there is the experimental uncertainty of the individual measurements. Secondly, there is an uncertainty due to the fact that measurements of $\mathrm{OH}$ and its precursors are not strictly simultaneously and not in the same air parcel. For example, $\mathrm{OH}$ is determined with the long-path-absorption-technique sampling a volume of several $\mathrm{km}$ length and a diameter of less than a meter. The appropriate photolysis frequency is then the temporal and spatial average in this volume during the integration time of the $\mathrm{OH}$-experiment. However, the measurement of $\mathrm{J}_{1}$ took place at one end of the absorption path. As a measure of the statistical deviation between in-situ and long-path result we adopted the 10 min variance of the in-situ $J_{1}$. Similar arguments hold for the other support data are summarized in table 3.

The errors of the modeled $\mathrm{OH}$ were calculated solely from the propagation of these uncertainties. They were sampled by a simple Monte-Carlo technique. The error bars of the model are taken from the square root of the variance of the modeled $\left[\mathrm{OH}_{\mathrm{c}}\right]$. The dominating terms for the uncertainty of $\mathrm{OH}_{\mathrm{c}}$ stem from the experimental errors of $\mathrm{J}_{1}, \mathrm{O}_{3}, \mathrm{NO}_{2}, \mathrm{HCHO}$, and $\mathrm{CO}$. Systematic errors due to the 
uncertainties of the rate constants were not considered. The mean $\left\langle\left[\mathrm{OH}_{c}\right]\right\rangle$ and median $\left[\mathrm{OH}_{c}\right]_{m}$ were also calculated. A priori it is not clear whether $\left\langle\left[\mathrm{OH}_{c}\right]\right\rangle$ or $\left[\mathrm{OH}_{c}\right]_{m}$ give the more appropriate choice for the modeled hydroxyl radical concentration. For reasons of simplicity we rely on $\left[\mathrm{OH}_{c}\right]$, which is always directly determined from experimental input as given in table 1. It should be noted that $\left[\mathrm{OH}_{\mathrm{o}}\right]_{\mathrm{m}}$ reflects more realistically the influence of experimental uncertainties and the spatial distribution of the precursors along the light path. Worst case estimates of the influence of a spatially inhomogeneous $\mathrm{NO}_{x}$ concentrations were already discussed by Platt et al. (1988). The non linear dependencies of the $\mathrm{OH}$ concentration in particular from $\left[\mathrm{NO}_{x}\right]$ induce a systematic deviation of $\left\langle\left[\mathrm{OH}_{\mathrm{o}}\right]\right\rangle$ and $\left[\mathrm{OH}_{c}\right]_{m}$ from directly determined $\left[\mathrm{OH}_{c}\right]$. For example, $\left[\mathrm{OH}_{c}\right]_{m}$ is smaller than $\left[\mathrm{OH}_{0}\right]$ by about $8 \%$ for the Deuselbach/Schauinsland data. The mean $\left\langle\left[\mathrm{OH}_{0}\right]\right\rangle$ and median $[\mathrm{OH}]_{\mathrm{m}}$ practically coincide (the mean is $2 \%$ larger than the median for all campaigns). Since all three quantities are highly correlated $(r>0.99)$ a particular choice does not affect the correlation with the measured [OH].

Though figure 3 shows positive correlation between $[\mathrm{OH}]$ and $\left[\mathrm{OH}_{0}\right]$, the coefficient $\mathrm{r}\left(\mathrm{OH}, \mathrm{OH}_{\mathrm{o}}\right)$ is only 0.73 with a $95 \%$ confidence interval of $0.38 \ldots 0.89$, i.e. not better than the one for the correlation between measured $\mathrm{OH}$ and $\mathrm{J}_{1}$.

This is not surprising since the experimental uncertainty of the $\mathrm{OH}$-measurement already limits the degree of correlation that could be achieved (see appendix). Applying eq(A1) to $[\mathrm{OH}](=\mathrm{x}),\left[\mathrm{OH}_{\mathrm{c}}\right],(=\mathrm{y})$, and $J_{1}(=\mathrm{y})$ with $\mathrm{s}_{\mathrm{f}}=2.0 \cdot 10^{6} \mathrm{~cm}^{-3}$ (accounting only for the experimental uncertainty of $[\mathrm{OH}]$ and neglecting the smaller errors of $\left[\mathrm{OH}_{0}\right]$ and $\mathrm{J}_{1}$, resp.) and $\mathrm{s}_{\mathrm{OH}}=2.1 \cdot 10^{6} \mathrm{~cm}^{-3}$ leads to a mean upper bound of $r=0.72$ in both cases.

The comparison in figure 3 validates the model in the sense that the calculated and measured $\mathrm{OH}$ concentrations agree in magnitude. There is, however, the tendency for the model to slightly overestimate the $\mathrm{OH}$ concentration. To quantify the overprediction we use a least-squares fit

$$
[\mathrm{OH}]=a\left[\mathrm{OH}_{c}\right]+b
$$

for $a$ and $b$. Disregarding the outlier marked by an asterisk in figure 3 , we obtain 
$a=0.83( \pm 0.05)$ if the offset $b$ is suppressed and $a=0.79( \pm 0.12)$, $b=0.21( \pm 0.64) \cdot 10^{6} \mathrm{~cm}^{-3}$ otherwise. The least-squares minimisation is not a statistically consistent estimator for the slope (see for example Schneeweiß et al., 1986) since it underestimates the true $a$ in the present case, where the independent variable, $\left[\mathrm{OH}_{c}\right]$, has a finite error. In fact $[\mathrm{OH}]$ and $\left[\mathrm{OH}_{c}\right]$ have uncertainties of similar magnitude and cause. In such a case the change of $[\mathrm{OH}]$ to the independent variable gives another check of the slope

$$
\left[\mathrm{OH}_{c}\right]=a_{c}[\mathrm{OH}]+b_{c}
$$

and provides a second value for $a=a_{a}^{-1}=0.88( \pm 0.08)$ for $b=0$ and $a=1.06( \pm 0.2) b=-1.0( \pm 0.65) \cdot 10^{6} \mathrm{~cm}^{-3}$. As discussed the least squares fit underestimates $a_{0}$ and therefore $a=a_{0}^{-1}$ overestimates the true a. Both estimates for $b$ indicate that $b=0$ is likely to be a good choice. Then the inverse fit of the slope in eq(2) nicely confirms the first estimate. On average the model overpredicts $\mathrm{OH}$ by $20 \%$.

Note that the overprediction depends on the definition of $\left[\mathrm{OH}_{\mathrm{c}}\right]$. As already mentioned, the median of the $\mathrm{OH}_{\mathrm{c}}$ distribution is smaller and would reduce the overprediction to $10 \%$. In any case this difference is surprisingly small in view of the many experimental and statistical uncertainties.

\subsection{The Campaigns under Moderately Polluted Conditions}

Preliminary data of the campaigns in Jülich have already been discussed elsewhere (Ehhalt et al., 1991). Since then the calibration of the detector for the ozone photolysis has been improved, resulting in a small correction of the photolysis frequency, which has now an estimated total uncertainty of 26 percent. The dependence of the measured $\mathrm{OH}$ concentration on the measured ozone photolysis frequency is displayed in figure 4 . Since the $\mathrm{OH}$-concentrations are determined by a difference method, negative values may occur when the measured concentration approaches the $1-\sigma$ uncertainty which is indicated by the error bar. 


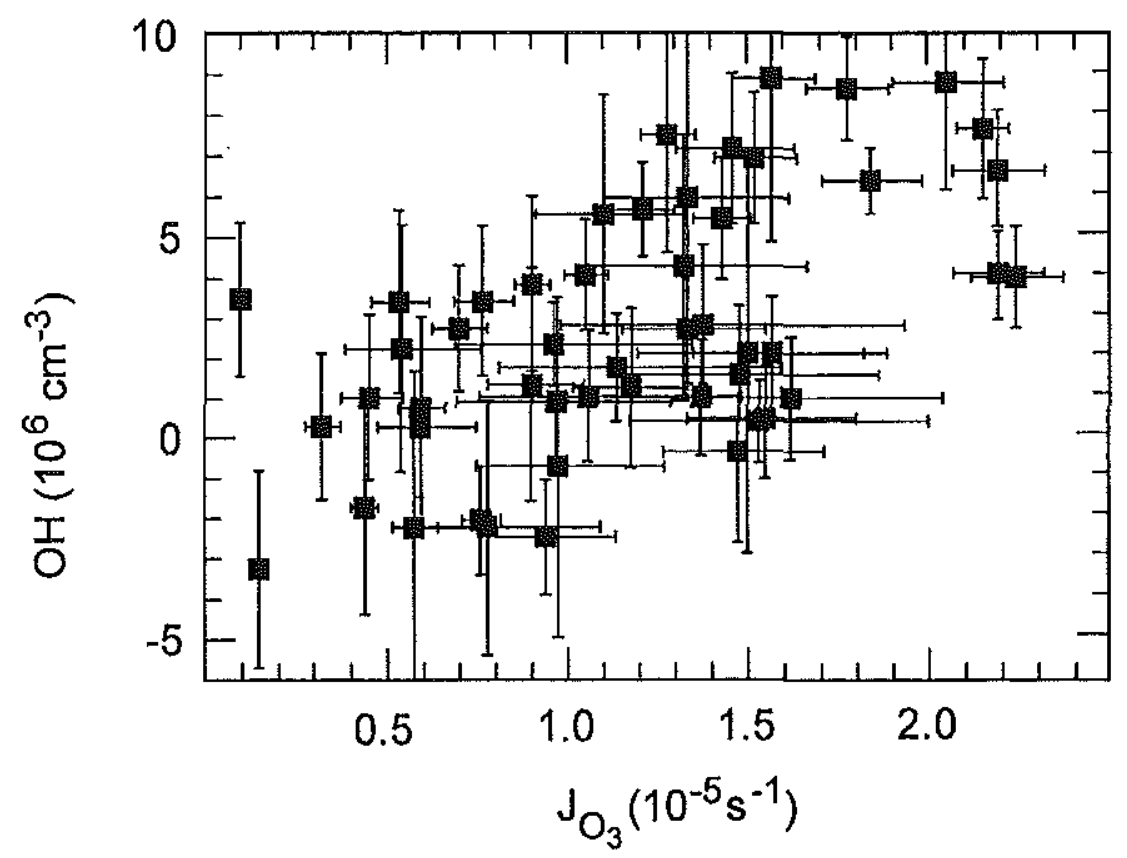

Fig. 4: Correlation of measured $\mathrm{OH}$ concentrations with simultaneously observed frequencies of the photolysis of ozone from the Jülich (1987 and 1988) campaigns. Error bars indicate the mean standard deviation. (Correlation coefficient $=0.58$ )

Despite instrumental improvements, the $\mathrm{OH}$ measurements made in Jülich in 1987 and 1988 still show error bars as large as the earlier measurements. This is partly due to a a shorter light path of only $6 \mathrm{~km}$, while in 1983 and 1984 the pathlengths were $9.6 \mathrm{~km}$ and $8.6 \mathrm{~km}$, resp. Moreover, the integration time for the $\mathrm{OH}$ measurement was reduced to improve the temporal resolution. Another reason is the presence of gases like $\mathrm{SO}_{2}$ and $\mathrm{HCHO}$ which are known to have absorption features overlapping with the $\mathrm{OH}$ absorption lines and require corrections that result in increased uncertainties. In addition, there are yet unidentified features within the spectral range of the $\mathrm{OH}$ lines which add to the current overall uncertainty. Identification and characterisation of the unknown features will lead to smaller errors, possibly also to small changes in the measured $\mathrm{OH}$ concentrations. These changes, however, should well remain within the current error estimates.

In contrast to the campaigns with a low burden of pollutants, we now observe a weaker correlation between measured $\mathrm{OH}$ and $\mathrm{J}_{1}$ with $\mathrm{r}\left(\mathrm{OH}, \mathrm{J}_{1}\right)=0.58$ and a $95 \%$ confidence interval of $0.36 \ldots 0.74$, while the model gives $r\left(\mathrm{OH}_{c}, J_{1}\right)=0.75$. Both 
correlations are smaller than for the low pollution case (see $\sec 6.1$ ). This finding could be partly due to the lower average ozone photolysis frequency of $\left\langle J_{1}\right\rangle=1.2 \cdot 10^{-5} \mathrm{~s}^{-1}$, whereas Deuselbach/Schauinsland had $\left\langle J_{1}\right\rangle=1.6 \cdot 10^{-5} \mathrm{~s}^{-1}$. Lower $\mathrm{J}$-values tends to increase the relative importance of other $\mathrm{OH}$ radical sources. Assuming a linear relation according to eq(A1) with $s_{O H}=2.4 \cdot 10^{6} \mathrm{~cm}^{-3}$ and $\mathrm{s}_{1}=2.0 \cdot 10^{6} \mathrm{~cm}^{-3}$ we would obtain $\mathrm{r}=0.77$, which is larger than the experimental correlation coefficient. Consequently, in addition to the known experimental uncertainties there must be other causes for the variance of the measured $[\mathrm{OH}]$. The correlation diagram for measured and modeled $\mathrm{OH}$ (figure 5) shows also a weak correlation with $\mathrm{r}\left(\mathrm{OH}, \mathrm{OH}_{\mathrm{o}}\right)=0.61$ with a $95 \%$ confidence interval of $0.39 \ldots 0.76$. Thus the chemistry as implemented in RADM2 and as initialized by the measured data does not help to explain the remaining variance of $[\mathrm{OH}]$.

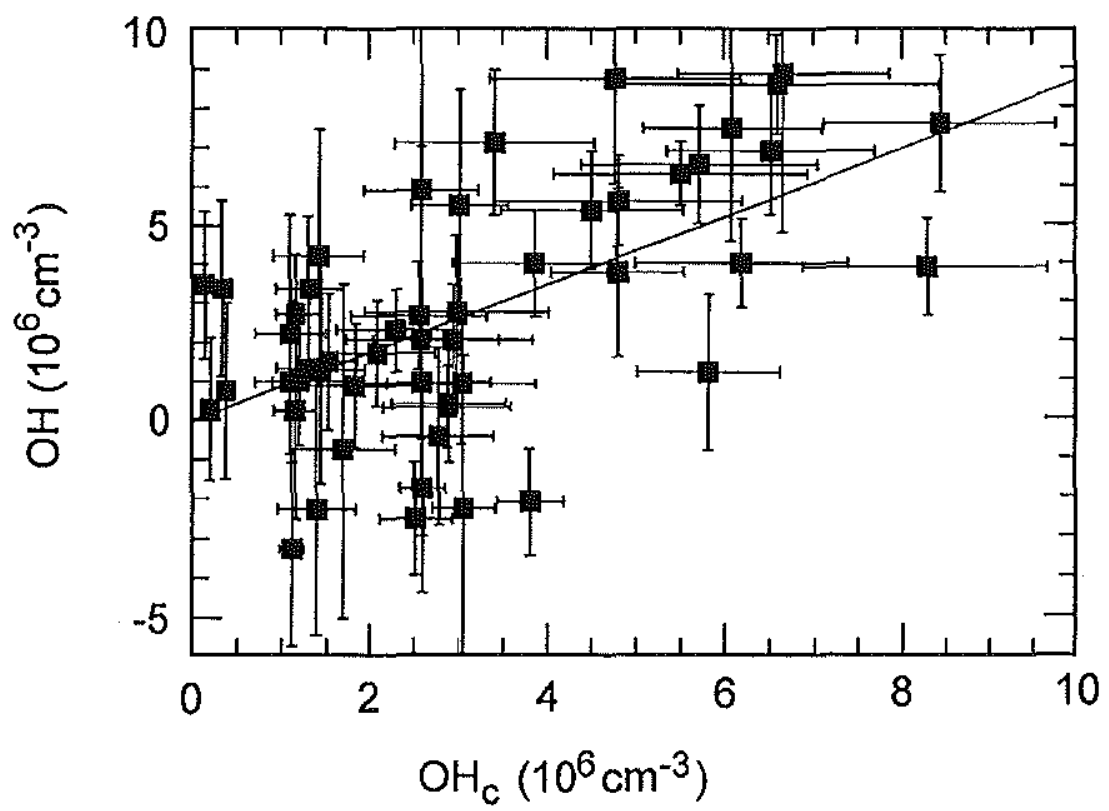

Fig. 5: $\quad$ Correlation of measured and calculated $\mathrm{OH}$ concentrations at Jülich (1987 and 1988). The error bars represent the mean standard deviations. (Correlation coefficient $=0.61$ ).

A possible reason could be the simplified treatment of the NMHC (see table 2) in the calculations as discussed in section 5 . In figure $6\left[\mathrm{OH}_{\mathrm{c}}\right]$ calculated using the correlations and calculated using the full set of measured hydrocarbons are compared. 


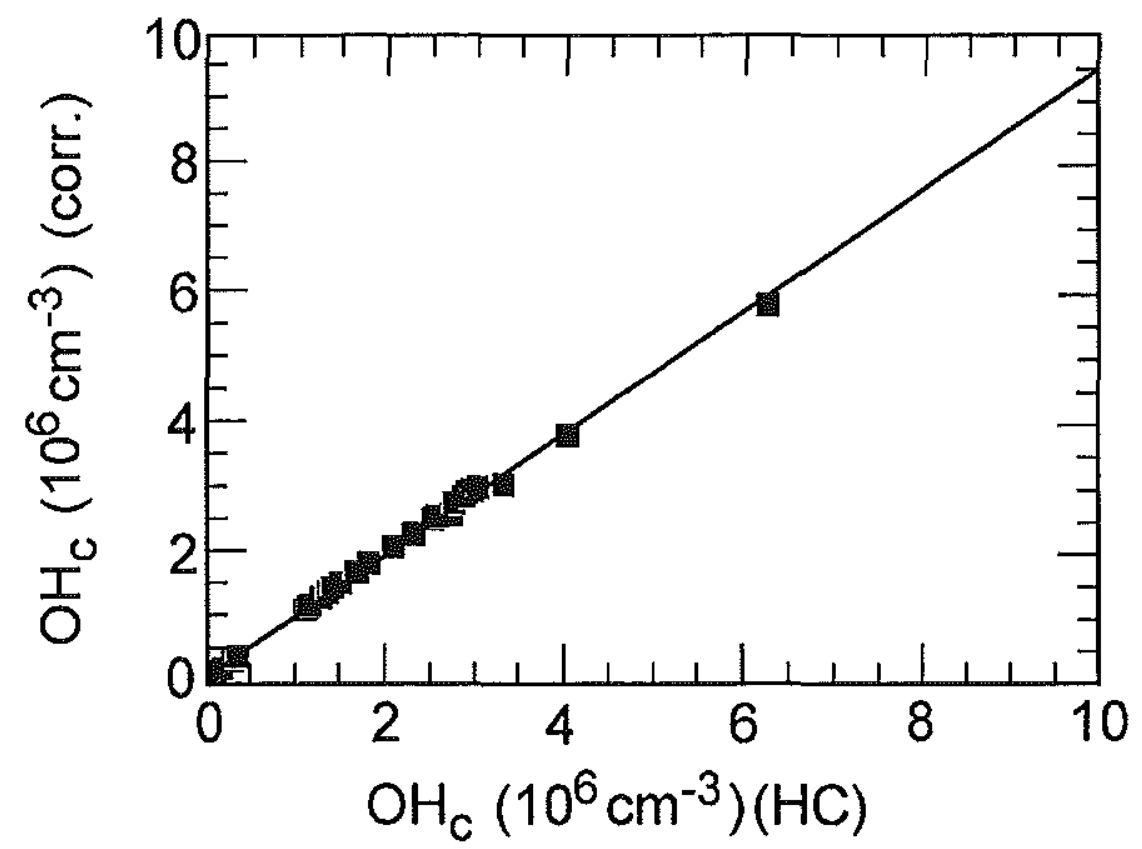

Fig. 6: Comparison of $\left[\mathrm{OH}_{\mathrm{C}}\right.$ ] of the Jülich campaign in 1988. The abszissa contains $\left[\mathrm{OH}_{C}\right]$ calculated using all measured hydrocarbons, the ordinate gives $\left[\mathrm{OH}_{\mathrm{a}}\right.$ calculated using the relations of table 2 (correlation coefficient $=0.999$ ).

Excellent agreement with individual differences not larger than $6 \%$ indicates that the approximate treatment (table 2) of the measured hydrocarbons is not responsible for the remaining variance. Since individual NMHC measurements deviate substantially from the approximate relations of table 2, this result reflects the relatively small impact of the measured NMHC on the $\mathrm{OH}$ concentration.

The statistical model eq(1) adopting $b=0$ is used to compare measured and modeled $\mathrm{OH}$. The slope is $a=0.87 \mathrm{implying} 15 \%$ overprediction by the model. This result is supported by comparing the mean values. The measured $\mathrm{OH}$ concentration is $2.7 \cdot 10^{6} \mathrm{~cm}^{-3}$ while the mean calculated $\left[\mathrm{OH}_{\mathrm{C}}\right]$ is given by $3.1 \cdot 10^{6} \mathrm{~cm}^{-3}$ so that the model overpredicts $\mathrm{OH}$-concentrations by 15 percent. Previous comparisons by Ehhalt et al. (1991) and D.Poppe et al. (1992) have shown larger overpredictions. Since then many of the $\mathrm{OH}$ absorption spectra were reanalysed which yields an average increase of the measured $\mathrm{OH}$ concentrations (Poppe et al., 1993b).

The model overpredicts $\mathrm{OH}$ by the same amount for both types of campaigns. As already stated for the rural campaigns this discrepancy is surprisingly small in 
view of systematic uncertainties of the experiments and of the model due the uncertainties of the rate constants.

\subsection{Error Analysis of the Comparison}

So far we have only considered the non systematic errors of $\left[\mathrm{OH}_{6}\right]$ due to the experimental uncertainties of the precursors and $[\mathrm{OH}]$. There are inevitably also systematic errors of the experimental data for example due to calibration errors of the experimental method and of the model due to incorrect rate constants or missing chemistry. As will be discussed in the next section the systematic errors have only a minor influence on the correlation of $[\mathrm{OH}]$ and $\left[\mathrm{OH}_{\mathrm{c}}\right]$. They affect primarily the slope $a$ in eq(9) and its error. Here the contributions from erronous rate constants are considered. In order to estimate their influence on $\left[\mathrm{OH}_{\mathrm{c}}\right]$ we have performed calculations for both campaigns, where all rate constants were varied independently within the recommended uncertainties. Log normal distributions of the rate constants were assumed which were sampled by a Monte Carlo simulation. The frequency distribution of the slope of the linear regression of $[\mathrm{OH}]$ versus $\left[\mathrm{OH}_{\mathrm{o}}\right]$ forced to go through the origin is plotted in figure 7 . The shape for both types of campaigns are very similar and can be well approximated by log normal curves. The width of the distributions is a measure for the uncertainty inherent to the model. Since $a=1$ is enclosed by both frequency distributions there are numerous combinations of altered reaction constants which lead to agreement on the average. Therefore we cannot reject the hypothesis that the model within its error bounds and the field data agree on the average. The model is not capable of detecting discrepancies between model and experiment which are smaller than $30 \%$ for the campaigns in $83 / 84$ and $50 \%$ for the Jülich campaigns of $87 / 88$. A more decisive comparison requires necessarily improved kinetic data. 

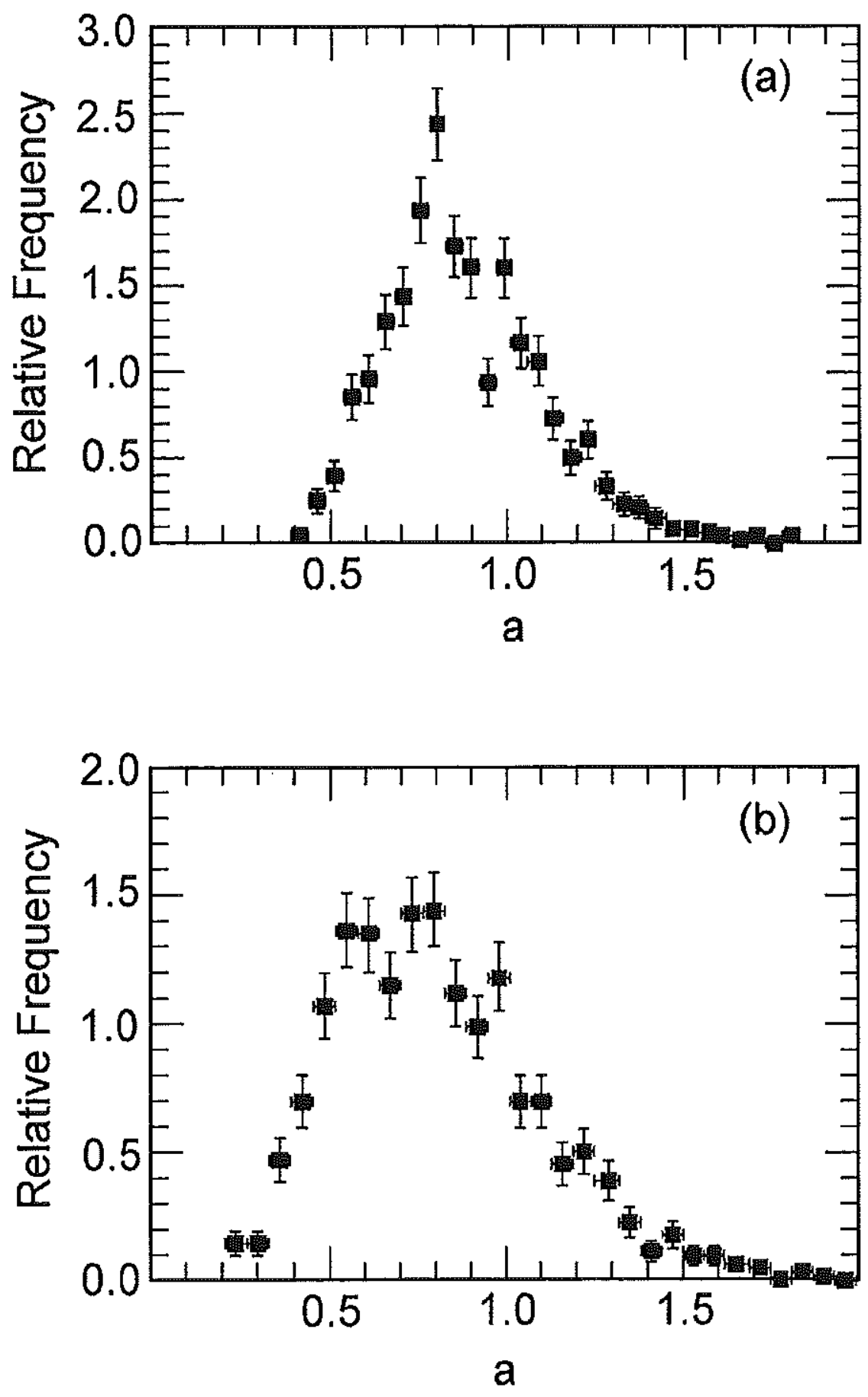

Fig. 7: Frequency distribution of the slope a of a linear regression $[\mathrm{OH}]=\mathrm{a}$ $\left[\mathrm{OH}_{\mathrm{a}}\right]$ if the rate constants of the RADM chemical scheme are variied randomly whithin the recommended uncertainties.
(a) rural campaigns 1983/84
(b) Jülich campaigns 1987/88

Since $\mathrm{OH}$ is strongly sensitive (see section 7 ) to a small number of reactions only their rate constant should be improved. For example zero error bars for the rate 
constants of the reaction of $\mathrm{OH}$ with $\mathrm{NO}_{2}$ (R4), of $\mathrm{CH}_{3} \mathrm{COO}_{2}$ with $\mathrm{NO}$ (R12), and the photolysis of $\mathrm{HCHO}$ (R9) reduce the width of the distribution in figure 7 considerably. For the Jülich data one would be able to detect discrepancies between model and experimental data which are larger than $26 \%$. Additional zero error bars of the $\mathrm{O}_{3}$-photolysis frequency (R1), the reaction constants for the oxidation of $\mathrm{NO}$ by $\mathrm{HO}_{2}(\mathrm{R} 8)$ and by $\mathrm{O}_{3}(\mathrm{R} 16)$, and $\mathrm{g}\left(\mathrm{eq}\left(1^{\prime}\right)\right)$ reduces the width of the distribution further to allow detection of discrepancies as small as $18 \%$.

\section{Discussion}

The most important results of the previous section can be summarized as follows:

- The model slightly overpredicts $\mathrm{OH}$ for both types of campaigns. The overprediction is within the errors from the uncertainties of the rate constants.

- The relatively small coefficient of correlation between $[\mathrm{OH}]$ and $\left[\mathrm{OH}_{6}\right]$ can be explained by the experimental uncertainties.

- The precision of the comparison is limited by the uncertainties of the rate constants.

- For the Jülich campaigns the correlation between model and field data is smaller than expected from the experimental uncertainties. In other words, there is unexplained variance in $[\mathrm{OH}]$ with respect to $\left[\mathrm{OH}_{0}\right]$.

Our discussion will mainly focus on the last point.

\subsection{Sensitivity Studies}

We begin with a sensitivity study to explore the relative importance of the measured data towards $\mathrm{OH}$ in order to improve the understanding of the radical chemistry during the campaigns. The sensitivity in 1 . order with respect to a parameter $P$ is defined by

$$
s(P)=\frac{P}{[\mathrm{OH}]} \frac{d[\mathrm{OH}]}{d} P
$$


For instance, a functional dependence $[O H] \sim P^{n}$ leads to $s(P)=n$. The sensitivity coefficients were determined numerically from a finite difference scheme

$$
\mathrm{s}(\mathrm{P}) \approx \frac{[\mathrm{OH}(\mathrm{P}+\Delta \mathrm{P})-\mathrm{OH}(\mathrm{P}-\Delta \mathrm{P})]}{2 \Delta \mathrm{P}}
$$

where $\mathrm{OH}(\mathrm{P} \pm \Delta \mathrm{P})$ were calculated under steady state assumptions as described in section 5 . Tables 4 and 5 display $s(P)$ for all parameters with $|s|>0.05$ with the exception of the pressure for all data points of table 1. Many of the results in these tables can be qualitatively explained by the simple chemical scheme developed in section 2. Basically $\mathrm{NO}_{x}$ is the main controlling parameter of the radical chemistry. For high $\mathrm{NO}_{x}$ conditions (data point 40 and higher) during 1988 we find that $\mathrm{s}\left(\mathrm{NO}_{2}\right)$ is negative with values near -1 . The approximation eq(7a) yields $s\left(\mathrm{NO}_{2}\right)=-1$ if we neglect the small contribution from $\mathrm{CH}_{3} \mathrm{CHO}$. The large negative $\mathrm{s}\left(\mathrm{NO}_{2}\right)$ indicates nearly complete radical cycling. Therefore simultaneously $\mathrm{s}(\mathrm{CO})$ and $s$ (hydrocarbons) are very small in accordance with eq(7a). Medium $\left[\mathrm{NO}_{2}\right]$ and high ozone concentrations around $70 \mathrm{ppb}$ generate under photostationary conditions rather small [NO] and therefore incomplete radical cycling. The negative sensitivity with respect to $\mathrm{O}_{3}$ via $\mathrm{NO}$ overcompensates the positive impact of $\mathrm{O}_{3}$ via its photolysis. The sensitivity with respect to the $\mathrm{NO}_{2}$ photolysis frequency, $\mathrm{s}\left(\mathrm{J}_{15}\right)$, is always positive and decreases of course with increasing radical cycling efficiency. Under low $\mathrm{NO}_{x}$ conditions during the early campaigns the self reaction of the peroxyradicals lower the cycling of radicals evidenced by negative $\mathrm{s}(\mathrm{CO})$ and still negative but small $s\left(\mathrm{NO}_{2}\right)$. Data points 6 and 7 are the exception of this rule having very small $\mathrm{NO}_{2}$ mixing ratios of $0.6 \mathrm{ppb}$. Then $[\mathrm{OH}]$ increases with increasing concentration of $\mathrm{NO}_{2}$.

Common to all data points is the surprisingly small $s\left(J_{1}\right)$ indicating that besides the photolysis of $\mathrm{O}_{3}$ other radical sources are contributing, for example the photodissociation of formaldehyde (R9). The ratio $\mathrm{s}\left(\mathrm{J}_{9}\right) / \mathrm{s}\left(\mathrm{J}_{1}\right)$ indicates the influence of the $\mathrm{HCHO}$ - relative to the $\mathrm{O}_{3}$-photolysis. Note that always $\mathrm{s}(\mathrm{HCHO}) \sim \mathrm{s}\left(\mathrm{J}_{9}\right)$ which demonstrates that the dominant impact of $\mathrm{HCHO}$ is the 
photolysis and that the negative contribution to the sensitivity from the reaction of $\mathrm{OH}$ with formaldehyde is very small. Peroxyacetyl nitrate (PAN) chemistry acts as a temperature dependent source or sink of radicals (R13 and R14). Interestingly, for our data set, the measured PAN concentration exceeds its momentary steady state value so that the PAN reactions are always a radical source. As representative of the primary hydrocarbons the sensitivity towards propene is entered which is always negative but small. All other measured hydrocarbons yield similar or smaller sensitivities. The most important result of the sensitivity study is, however, that at least for these datasets $\left[\mathrm{OH}_{c}\right]$ is determined by only a small set of parameters.

\subsection{Correlations with Precursors}

The correlation of the most relevant parameters with the measured and modeled hydroxyl concentrations is a further test for the validity of the radical chemistry in the model. Indeed, agreement between model and experiment implies agreement between corresponding correlation coefficients $r$. In figure $8 r$ for the modeled and the measured $\mathrm{OH}$ are compared. 


\section{Correlation for $\mathrm{OH}$ in $83 / 84$}

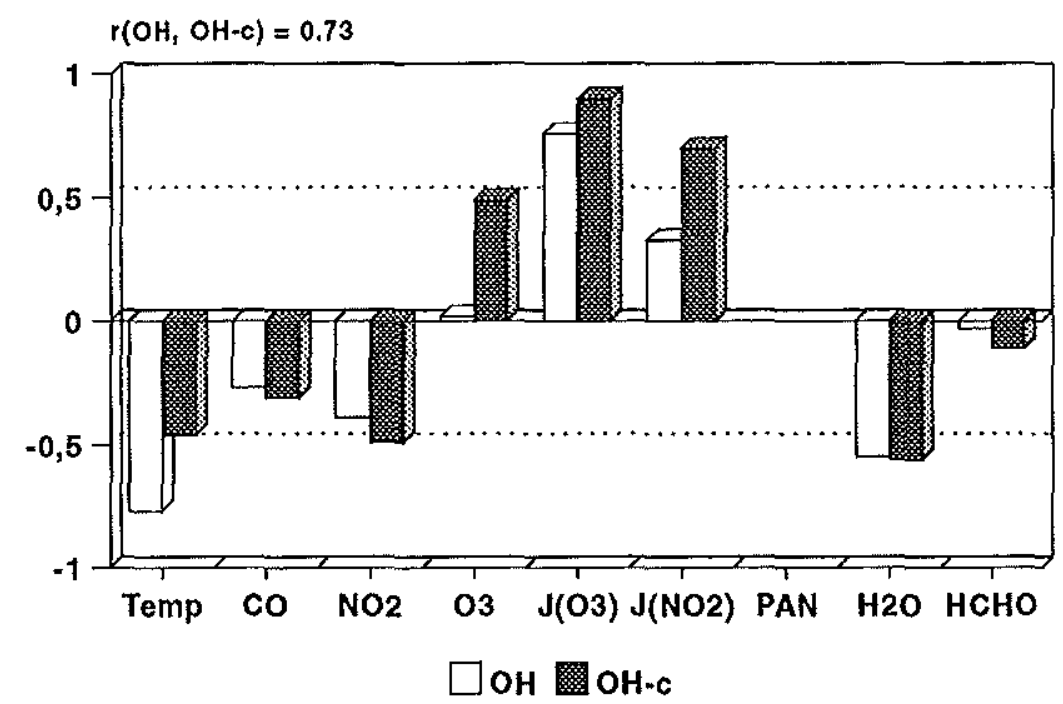

\section{Correlation for $\mathrm{OH}$ in $\mathbf{8 7 / 8 8}$}

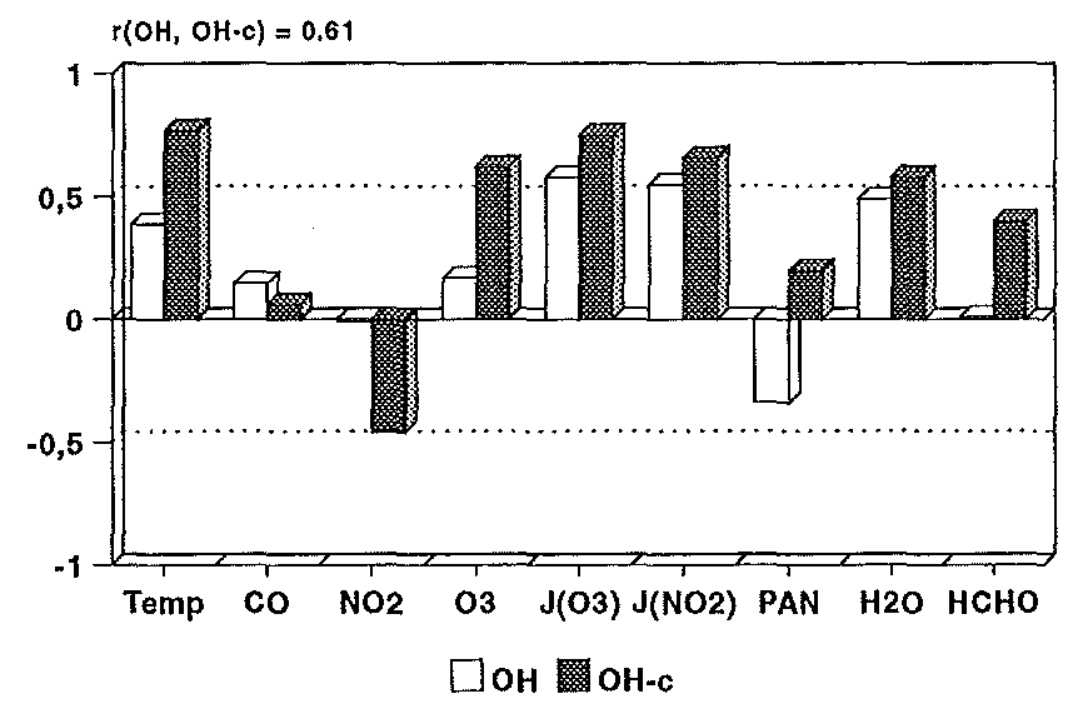

Fig. 8: Correlations of several precursors with the calculated and the measured $\mathrm{OH}$ concentration for the rural campaigns and the Jülich campaigns. $J(\mathrm{O} 3)=J_{1}, J(\mathrm{NO})=J_{16}$

Possibly considerable statistical errors of $r$ due to the finite data set are irrelevant, since both $r$ values are drawn from the very same data set. The actual values depend very much on the campaign and sometimes seem to contradict the 
sensitivity results. For example PAN (see table 4) in Jülich has always a positive $s(P A N)$, while $r$ is negative for $[\mathrm{OH}]$ and $\left[\mathrm{OH}_{c}\right]$. The reason is that the strong correlation among the precursors of $\mathrm{OH}$ can overcompensate a dependence which is infered from the sensitivity coefficient. [OH] has usually a positive sensitivity and correlation with respect to $J_{1}, J_{15},\left[\mathrm{O}_{3}\right]$, and $\left[\mathrm{H}_{2} \mathrm{O}\right]$.

In case of PAN the negative correlations of PAN with these parameters $\left(r\left(J_{1}, P A N\right)=-0.63, \quad r\left(J_{15}, P A N\right)=-0.56, \quad r\left(O_{3}, P A N\right)=-0.46, \quad r\left(H_{2} \mathrm{O}, P A N\right)=-0.78\right)$ counteracts the positive $s(P A N)$. With exception of the temperature during the campaign of $1983 / 84$ the absolute values of $r$ for $[\mathrm{OH}]$ are smaller than for $\left[\mathrm{OH}_{c}\right]$, which is to be expected, since experimental errors reduce the observed correlation. There is by and large good coincidence between both correlation coefficients which is further evidence for the validity of the chemical model. Only for ozone in both campaigns and $\mathrm{NO}_{2}$ in Jülich there are considerable differences pointing possibly to yet unknown inaccuracies or incompleteness of the chemical scheme.

The sensitivity analysis has another consequence. The relevant parameters are related to the generic types of reactions of the $\mathrm{OH}$ chemistry which were already discussed in section 2: production from photolytic sources, radical destruction, oxidation reactions accompanied by recycling of $\mathrm{OH}$, and radical losses due to recombination reactions of peroxy radicals. With respect to the model as it is the comparison of $\mathrm{OH}$ and $\mathrm{OH}_{\mathrm{c}}$ are only sensitive to these five factors. To explore their capability of explaining the remaining variance of the Jülich data we have conducted model calculations where all reaction constants belonging to a particular reaction path were scaled by a common factor $w$. The slope according to eq(9) with $b=0$ and the correlation of $[\mathrm{OH}]$ and $\left[\mathrm{OH}_{c}\right]$ are then investigated as function of $w$. For $0.1<w<10$ the correlation coefficient depends only slightly on $w$ with a variation smaller than a few percent for all factors. Consequently any reasonable change of reaction constants even beyond the recommended error bounds does not increase the correlation between $[\mathrm{OH}]$ and $\left[\mathrm{OH}_{c}\right]$ and is therefore not been able to explain the extra variance in the Jülich data.

The carbonyls, methylglyoxal, glyoxal, and the ketones, which are degradation products of the measured higher hydrocarbons have been neglected so far(see section 5 ). Their influence can be examined by assuming plausible values for their 
concentrations. Most likely upper bounds are provided by their steady state abundances. Then ketones reach mixing ratios up to $10 \mathrm{ppb}$, while the dicarbonyls, methylglyoxals and glyoxal are usually below $1 \mathrm{ppb}$. In figure 9 modeled $\mathrm{OH}$ concentrations using steady assumptions for these compounds are compared with $\mathrm{OH}$ calculations from section 6.2 for the Jülich campaigns. The correlation between both sets of modeled $\mathrm{OH}$ are large $(r=0.99)$ and the difference of $20 \%$ in the worst case is still small. Thus these compounds are not responsible for the extra variance.

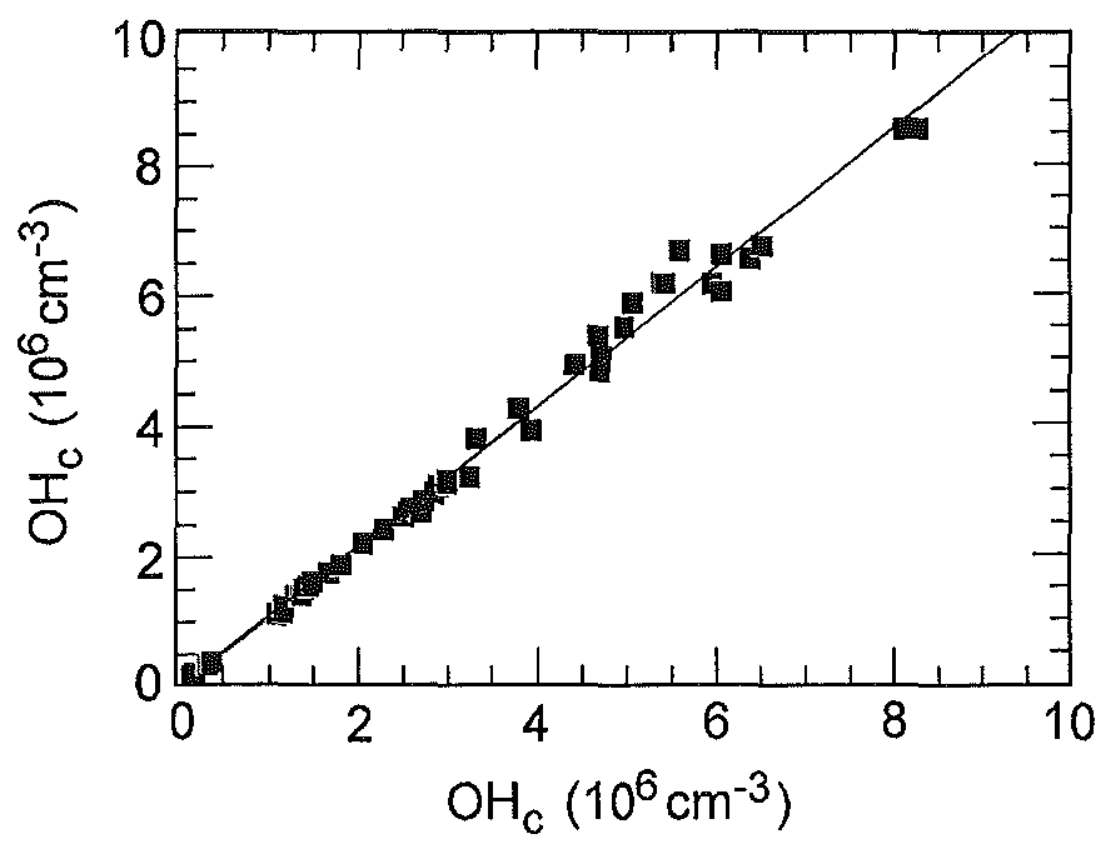

Fig. 9: Influence of dicarbonyls and ketones on the calculated $\mathrm{OH}$ concentration for the Jülich campaigns. $\left[\mathrm{OH}_{a}\right]$ for vanishing concentrations of these compounds (abszissa) and $\left[\mathrm{OH}_{a}\right.$ for steady state concentrations of them (ordinate).

So far no heterogeneous processes affecting the radical budget and the discussed variance have been considered. As an example we discuss the loss of $\mathrm{HO}_{2}$ radicals on aerosol surfaces. Adopting an aerosol surface density $\mathrm{F}<10^{-3} \mathrm{~m}^{-1}$ which is representative for continental clean air (Withby, 1978, Logan et al., 1981) and might ever be larger for Jülich, a sticking coefficient of unity (see however Mozurkewich et al., 1987), and a thermal velocity of $\mathrm{HO}_{2}$ of $110 \mathrm{~m} / \mathrm{s}^{-1}$ we obtain an upper bound for the $\mathrm{HO}_{2}$ decay rate on aerosol of $\mathrm{k}<0.11 \mathrm{~s}^{-1}$ 
Since the correlation between $[\mathrm{OH}]$ and $\left[\mathrm{OH}_{6}\right]$ is nearly independent of $k$, constant loss on aerosol offers no explanation for the extra variance. The slope (figure 10) according to eq $\left(11^{\prime}\right)$, however, indicates that such a loss can generate variance provided the loss rate $k$ itself is highly variable over at least one order of magnitude during the campaign.

An additional possible cause for the discrepancy is the presence of gases not measured and therefore not included into the model calculations. Measurements in rural and urban environments of the Eastern U.S. for example have shown high concentrations of natural hydrocarbons e.g. isoprene (R. S. Martin et. al. 1991).

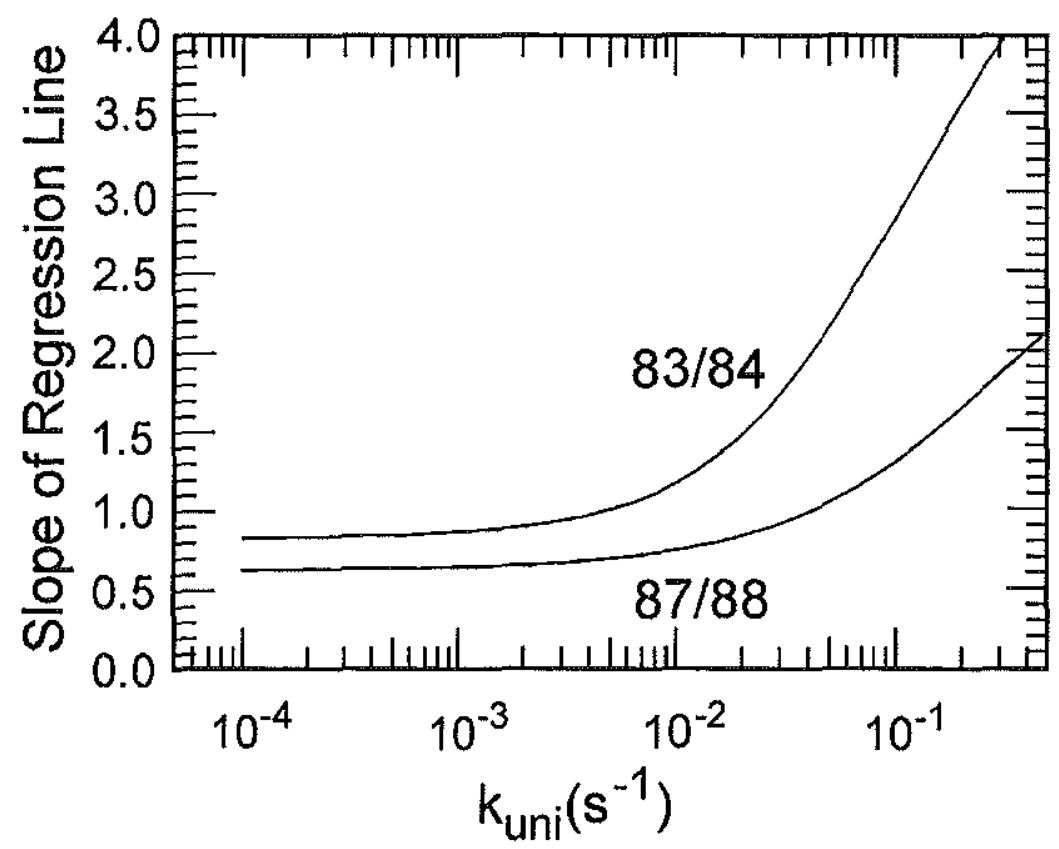

Fig. 10: Dependence of the slope a of a linear regression model $[\mathrm{OH}]=a\left[\mathrm{OH}_{d}\right.$ on the pseudo unimolecular decay $k_{u n i}$ of $\mathrm{HO}_{2}$ on aerosol particles.

The unaccounted influence of isoprene in concentrations observed there could be responsible for the present deviations between $[\mathrm{OH}]$ and $\left[\mathrm{OH}_{\mathrm{c}}\right]$. Figure 11 gives an estimate of the possible impact of isoprene on the $\mathrm{OH}$ by comparing $\left[\mathrm{OH}_{\mathrm{c}}\right]$ calculated without isoprene and $\left[\mathrm{OH}_{c}\right]$ calculated with an isoprene mixing ratio of $4 \mathrm{ppb}$. Since the most important controlling parameter for isoprene emission, the temperature, was always below $26^{\circ} \mathrm{C}$ with an average of $19^{\circ} \mathrm{C}$, this mixing ratio is likely to be too large. Even the fixed isoprene concentration for all data is capable of generating variance with respect to the calculations without isoprene. The 
reason is that isoprene if present in the ppb-range has such a severe impact on the partitioning of radicals between $\mathrm{OH}$ and $\mathrm{HO}_{2}$ that it can alter the relative importance of the radical loss in $\mathrm{R} 11$ and the reactions of $\mathrm{HO}_{2}$ with $\mathrm{HO}_{2}$ and $\mathrm{RO}_{2}$. Since the isoprene concentration, though likely to be smaller than $4 \mathrm{ppb}$, was not measured we cannot exclude this reactive hydrocarbon as a contributor to the variance of $[\mathrm{OH}]$. Note, that the average hydroxyl concentration under the isoprene burden decreases only slightly.

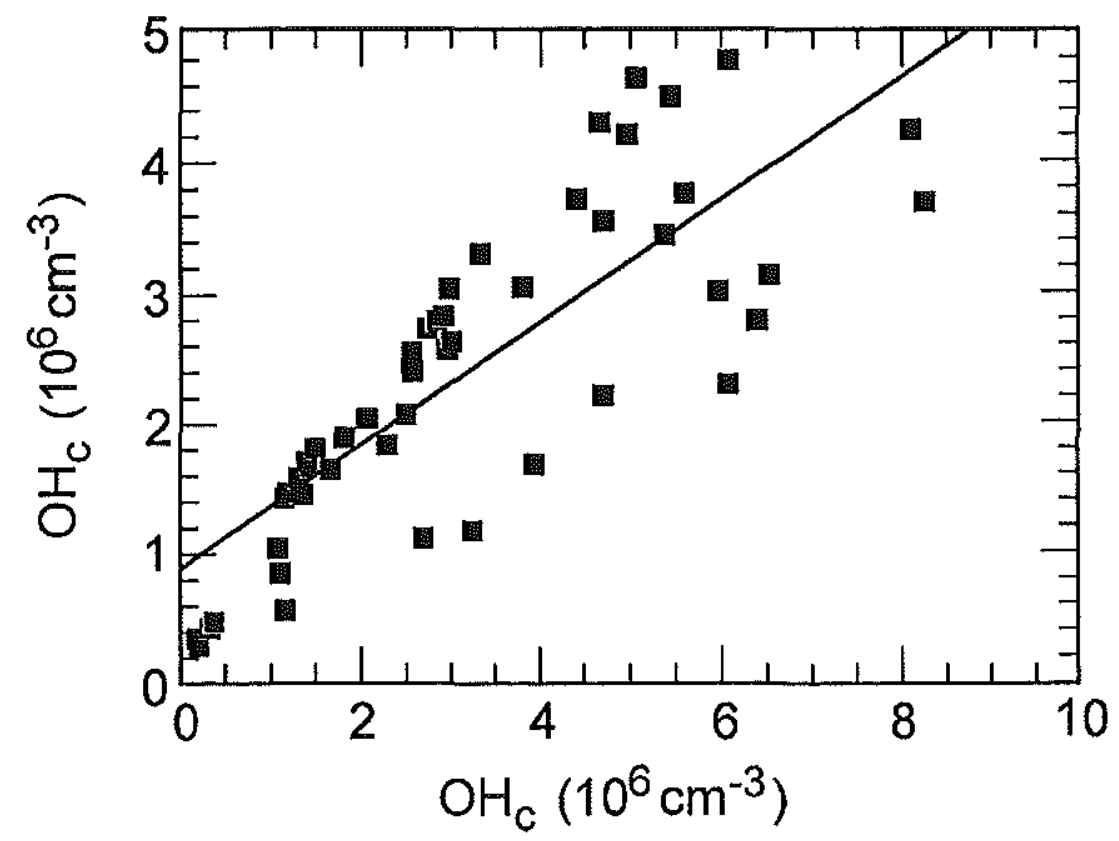

Fig. 11: Influence of isoprene on the calculated $\mathrm{OH}$ concentration for the Jülich campaigns. [OH] for an isoprene mixing ratio of $4 \mathrm{ppb}$ (ordinate) and $\left[\mathrm{OH}_{\mathrm{a}}\right]$ for vanishing isoprene (abszissa).

Finally, a source of variance which is not accounted for is the possible inapplicability of a zero-dimensional model under the environmental conditions in Jülich. In contrast to the fairly homogeneous environment of the rural campaigns in Deuselbach and Schauinsland, the site in Jülich is rather structured with respect to poliutant sources. Spatial homogeneity is not always experienced by the air parcels passing the experimental site. In this case, the steady-state assumption, which requires constant precursor concentrations and meteorological conditions within the parcel over several chemical relaxation times, is no longer valid. A study of the implications of non-stationarity on $[\mathrm{OH}]$ is in progress. 
conditions within the parcel over several chemical relaxation times, is no longer valid. A study of the implications of non-stationarity on $[\mathrm{OH}]$ is in progress.

\section{Summary}

Measurements of the hydroxyl concentrations in chemically well characterized air masses have been compared with model calculations using a comprehensive reaction mechanism for the gas phase chemistry of the troposphere. The comparison reveals agreement on the average for the field data from the campaigns under rural and moderately polluted conditions. The model slightly overpredicts $\mathrm{OH}$ by about $20 \%$, which is well within the systematic uncertainties of the measured $\mathrm{OH}$ and calculated $\mathrm{OH}$ due to uncertain rate constants. Correlations of $\mathrm{OH}$ and $\mathrm{OH}_{\mathrm{o}}$ with meteorological parameters, photolysis frequencies, and chemical precursors coincide so that the calculations also model these dependencies basically correct. Discrepancies in particular for $\mathrm{O}_{3}$ indicate possible inadequacies of the model. However, since all these results are based on a statistical analysis of a relatively small number of data points, more data are needed before one could draw more firm and specific conclusions.

It should be pointed out that the study and its results are limited to near surface air with weak and moderate pollutions. It should be complemented by investigations in different environments, for example the free troposphere and the marine boundary layer, to explore the $\mathrm{OH}$ chemistry for a wider range of chemical conditions.

\section{Acknowledgement}

Financial support the Bundesminister für Forschung und Technologie under grant $07 \mathrm{EU} 728 / 0$ is gratefully acknowledged. 


\section{$9 \quad$ Appendix}

Consider a linear model in the statistical sense for the variables $x$ and $y$

$$
y=a(x+f)
$$

where $f$ denotes the experimental errors of $x$ and $y$. Neglecting $f$ the correlation coefficient, $r$, of $x$ and $y$ is unity. Including fyields a smaller $r$

$$
r=\frac{1}{\sqrt{1+\left(\frac{s_{1}}{s_{x}}\right)^{2}}}
$$

Here $s_{x}{ }^{2}$ and $s_{f}{ }^{2}$ are the true variances of $x$ and $f$. Clearly, $r$ in eq(A2) can be considered as an estimate for the true $r$ if both variances are replaced by their corresponding estimates from a finite sample. Moreover, if not all experimental errors are included in $f, r$ gives an estimate of a mean upper bound of the true $r$. 
Table 1: Experimental data" of the campaigns in Deuselbach (1983), Schauinsland (1984), and Jülich (1987/88). Time is given in UT.

\begin{tabular}{|c|c|c|c|c|c|c|c|c|c|c|c|c|c|}
\hline No & date & UT/h & $\begin{array}{l}\mathrm{H}_{2} \mathrm{O} \\
\text { (a) }\end{array}$ & $\begin{array}{l}J\left(\mathrm{O}_{3}\right) \\
(\mathrm{b})\end{array}$ & $\begin{array}{c}J\left(\mathrm{NO}_{2}\right) \\
(\mathrm{c})\end{array}$ & $\begin{array}{l}T / C \\
\text { (d) }\end{array}$ & $\begin{array}{l}\mathrm{O}_{3} \\
\text { (d) }\end{array}$ & $\begin{array}{l}\mathrm{NO}_{2} \\
\text { (d) }\end{array}$ & $\begin{array}{l}\mathrm{HCHO} \\
\text { (d) }\end{array}$ & $\begin{array}{c}\mathrm{CH}_{3} \mathrm{CHO} \\
\text { (d) }\end{array}$ & $\begin{array}{l}\mathrm{C}_{3} \mathrm{H}_{3} \\
\text { (d) }\end{array}$ & $\begin{array}{l}\text { Co } \\
\text { (d) }\end{array}$ & $\begin{array}{l}\text { PAN } \\
\text { (d) }\end{array}$ \\
\hline \multicolumn{14}{|c|}{1983 Deuselbach } \\
\hline 1 & 17.5. & $9: 38$ & 2,74 & 0.78 & 3.60 & 14.5 & 41 & 2.20 & 0.90 & $0.60^{*}$ & $0.70^{*}$ & 270 & $\ldots$. \\
\hline 2 & 18.5. & $11: 32$ & 2.11 & 1.64 & 7.60 & 17.2 & 40 & 7.80 & $0.70^{*}$ & $0.60^{*}$ & $1.00^{*}$ & 360 & $\cdots$ \\
\hline 3 & 18.5. & 13:04 & 2.08 & 1.08 & 5.70 & 17.0 & 42 & 3.60 & $0.70^{*}$ & $0.50^{*}$ & $0.70^{*}$ & 280 & $\ldots$ \\
\hline 4 & 18.5. & $14: 58$ & 1.96 & 0.55 & 5.00 & 17.2 & 46 & 1.30 & 0.70 & $0.50^{*}$ & 0.50 & 240 & $\ldots$ \\
\hline 5 & 19.5. & $12: 12$ & 2.10 & 1.26 & 6.20 & 15.0 & 48 & 1.00 & 0.30 & $0.20^{*}$ & 0.50 & 260 & $\ldots$ \\
\hline 6 & 19.5. & $13: 52$ & 2.03 & 0.97 & 6.10 & 16.2 & 50 & 0.60 & 0.30 & $0.20^{*}$ & 0.40 & 230 & $\ldots$ \\
\hline 7 & 19.5 . & $14: 57$ & 1.96 & 0.67 & 5.90 & 16.4 & 52 & 0.60 & 0,30 & $0.20^{*}$ & 0.40 & 220 & $\ldots$. \\
\hline 8 & 20.5 . & $9: 18$ & 2.27 & 1.14 & 6.50 & 18.5 & 53 & 1.60 & 0.50 & $0.40^{*}$ & $0.60^{*}$ & 290 & $\ldots$. \\
\hline 9 & 20.5 . & $11: 17$ & 2.13 & 1.86 & 8.00 & 21.9 & 57 & 1.50 & 0.60 & $0.50^{*}$ & 0.54 & 250 & .... \\
\hline \multicolumn{3}{|c|}{ mean } & 2.15 & 1.11 & 6.07 & 17.1 & 47 & 2.24 & 0.56 & 0.41 & 0.59 & 267 & \\
\hline \multicolumn{14}{|c|}{1984 Schauinsland } \\
\hline 10 & 25.6. & $9: 20$ & 1.65 & 2.30 & 8.20 & 10.5 & 50 & 0.40 & 0.60 & 0.08 & 0.39 & $230^{*}$ & $\cdots \cdot$. \\
\hline 11 & 25.6. & 10:03 & 1.62 & 2.90 & 8.80 & 10.5 & 49 & 0.63 & 0.63 & $0.10^{*}$ & $0.50^{*}$ & $230^{*}$ & $\ldots$. \\
\hline 12 & 25.6 . & $10: 53$ & 1.56 & 2.40 & 6.70 & 10.2 & 49 & 1.00 & 0.33 & $0.13^{*}$ & 0.52 & $230^{*}$ & $\ldots$ \\
\hline 13 & 25.6. & $11: 44$ & 1.66 & 2.90 & 7.80 & 11.6 & 47 & 0.81 & 0.42 & $0.16^{*}$ & 0.52 & $230^{*}$ & $\ldots$ \\
\hline 14 & 25.6. & $12: 36$ & 1.67 & 2.60 & 7.30 & 11.0 & 50 & 0.59 & 0.59 & 0.18 & $0.50^{*}$ & $230^{*}$ & $\ldots$ \\
\hline 15 & 25.6. & $13: 35$ & 1.75 & 1.90 & 6.60 & 10.5 & 49 & 0.54 & 0.68 & $0.19^{*}$ & $0.50^{*}$ & $230^{*}$ & $\cdots$ \\
\hline 16 & 25.6. & $15: 16$ & 1.93 & 0.70 & 3.50 & 11.2 & 48 & 0.75 & 0.73 & $0.20^{*}$ & $0.50^{*}$ & $230^{*}$ & $\ldots$ \\
\hline 17 & 26.6. & $11: 51$ & 2.42 & 2.00 & 5.80 & 14.7 & 47 & 2.20 & 1.20 & 0.29 & 0.63 & $350^{*}$ & $\ldots$ \\
\hline \multirow{2}{*}{\multicolumn{14}{|c|}{$\begin{array}{r}\text { mean } \\
\text { 1987 Jülich }\end{array}$}} \\
\hline & & & & & & & & & & & & & \\
\hline 18 & 5.7 . & $10: 58$ & 3.20 & 2.30 & 7.80 & 23.1 & 48 & 4.40 & 0.80 & $0.80^{*}$ & 1.53 & 309 & $\cdots$ \\
\hline 19 & 5.7. & $12: 54$ & 3.20 & 2.09 & 7.30 & 24.1 & 54 & 4.00 & 0.80 & $0.80^{*}$ & $1.50^{*}$ & $300^{*}$ & $\ldots$ \\
\hline 20 & 5.7. & $13: 54$ & 3.10 & 1.74 & 6.80 & 24.6 & 62 & 4.50 & 1.20 & $1.00^{*}$ & $1.50^{*}$ & $300^{*}$ & $\cdots$ \\
\hline 21 & 5.7. & $14: 27$ & 3.00 & 1.43 & 6.30 & 24.8 & 60 & 4.30 & 1.40 & $1.00^{*}$ & $1.50^{*}$ & $300^{*}$ & $\cdots$ \\
\hline 22 & 5.7. & $15: 10$ & 2.90 & 1.05 & 5.80 & 24.9 & 59 & 3.70 & 1.40 & $1.00^{*}$ & $1.50^{*}$ & $250^{*}$ & $\ldots$ \\
\hline 23 & 11.7. & $9: 15$ & 3.30 & 1.46 & 5.80 & 23.1 & 56 & 5.70 & 1.00 & $1.00^{*}$ & $1.80^{*}$ & $300^{*}$ & $\ldots$ \\
\hline 24 & 11.7. & $10: 32$ & 3.10 & 2.05 & 6.80 & 24.0 & 53 & 5.00 & 1.20 & $1.00^{*}$ & $1.80^{*}$ & $300^{*}$ & $\ldots$ \\
\hline 25 & 11.7. & $11: 31$ & 3.01 & 2.19 & 7.00 & 24.7 & 29 & 2.10 & 0.75 & $0.70^{*}$ & $1.00^{*}$ & 189 & .... \\
\hline 26 & 11.7. & $12: 31$ & 3.50 & 1.84 & 6.40 & 25.0 & 33 & 2.20 & 0.70 & $0.70^{*}$ & $1.00^{*}$ & $200^{*}$ & $\ldots$. \\
\hline 27 & 11.7. & $14: 36$ & 3.90 & 1.21 & 5.60 & 25.7 & 54 & 3.80 & 1.25 & $0.70^{*}$ & $1.00^{\circ}$ & $200^{*}$ & $\cdots$ \\
\hline 28 & 14.7. & $11: 17$ & 3.50 & 2.19 & 6.90 & 22.6 & 56 & 4.00 & 1.00 & $0.70^{*}$ & 1.10 & 189 & $\ldots$ \\
\hline 29 & 14.7. & $12: 10$ & 3.50 & 2.24 & 7.00 & 23.3 & 63 & 2.70 & 0.90 & $0.70^{*}$ & 1.10 & 189 & $\ldots$ \\
\hline 30 & 14.7. & $12: 43$ & 3.40 & 2.15 & 6.90 & 23.5 & 67 & 2.30 & 0.80 & $0.70^{*}$ & $1.10^{*}$ & $190^{*}$ & $\cdots$ \\
\hline 31 & 14.7. & $13: 42$ & 3.40 & 1.52 & 5.80 & 24.3 & 73 & 2.30 & 0.90 & $0.70^{*}$ & $1.10^{*}$ & $200^{*}$ & $\ldots$ \\
\hline 32 & 14.7. & $14: 06$ & 3.40 & 1.57 & 5.80 & 24.6 & 75 & 2.70 & 1.00 & $0.70^{*}$ & $1.10^{*}$ & $200^{*}$ & $\ldots$ \\
\hline 33 & 14.7. & $14: 33$ & 3.80 & 1.28 & 5.60 & 24.7 & 78 & 2.90 & 1.00 & $0.70^{*}$ & $1.10^{*}$ & $200^{*}$ & $\ldots$ \\
\hline 34 & 14.7. & $15: 15$ & 3.80 & 0.90 & 4.90 & 24.8 & 82 & 2.60 & 1.00 & $0.70^{*}$ & $1.10^{*}$ & $200^{*}$ & $\cdots$ \\
\hline & & & 3.35 & 1.72 & 6.38 & 24.2 & 59 & 3.48 & 1.01 & 0.80 & 1.28 & 236 & \\
\hline \multicolumn{14}{|c|}{ Jülich } \\
\hline 35 & 15.5 & $13: 04$ & 2.70 & 1.18 & 4.47 & 25.1 & 73 & 2.44 & 2.03 & 0.29 & 1.08 & 243 & 1.25 \\
\hline 36 & 15.5. & $13: 35$ & 2.69 & 0.76 & 3.24 & 24.7 & 72 & 2.86 & 1.87 & 0.29 & 1.05 & 246 & 1.45 \\
\hline 37 & 15.5 & $14: 12$ & 2.74 & 0.57 & 2.74 & 24.7 & 71 & 2.30 & 1.71 & 0.29 & 1,02 & 258 & 1.54 \\
\hline 38 & 15.5. & $14: 53$ & 2.79 & 0.44 & 2.55 & 24.6 & 70 & 2.59 & 1.60 & 0.27 & 1.11 & 258 & 1.49 \\
\hline 39 & 15.5 & $16: 15$ & 2.76 & 0.15 & 1.42 & 24.0 & 73 & 2.91 & 1.57 & 0.24 & 1.26 & 265 & 1.60 \\
\hline 40 & 31.5. & $11: 47$ & 2.11 & 1.33 & 5.16 & 14.9 & 40 & 5.34 & 0.66 & 0.04 & 0.42 & 191 & 0.24 \\
\hline 41 & 31.5 & 12:03 & 2.01 & 1.48 & 6.06 & 15.1 & 39 & 5.35 & 0.65 & 0.04 & 0.41 & 197 & 0.24 \\
\hline 42 & 31.5. & $12: 25$ & 2.13 & 1.06 & 4.39 & 15.3 & 38 & 5.00 & 0.64 & 0.17 & 0.44 & 200 & 0.28 \\
\hline
\end{tabular}


(table 1 continued)

\begin{tabular}{|c|c|c|c|c|c|c|c|c|c|c|c|c|c|}
\hline No & date & UT/h & $\begin{array}{l}\mathrm{H}_{2} \mathrm{O} \\
\text { (a) }\end{array}$ & $\begin{array}{l}\mathrm{J}\left(\mathrm{O}_{3}\right) \\
\text { (b) }\end{array}$ & $\begin{array}{c}\mathrm{J}\left(\mathrm{NO}_{2}\right) \\
\text { (c) }\end{array}$ & $\begin{array}{l}T / C \\
\text { (d) }\end{array}$ & $\begin{array}{l}\mathrm{O}_{3} \\
\text { (d) }\end{array}$ & $\begin{array}{l}\mathrm{NO}_{2} \\
\text { (d) }\end{array}$ & $\begin{array}{l}\mathrm{HCHO} \\
\text { (d) }\end{array}$ & $\begin{array}{c}\mathrm{CH}_{3} \mathrm{CHO} \\
\text { (d) }\end{array}$ & $\begin{array}{l}\mathrm{C}_{3} \mathrm{H}_{3} \\
\text { (d) }\end{array}$ & $\begin{array}{l}\text { CO } \\
\text { (d) }\end{array}$ & $\begin{array}{l}\text { PAN } \\
\text { (d) }\end{array}$ \\
\hline 43 & 31.5 . & $14: 47$ & 2.19 & 0.76 & 4.95 & 15.4 & 39 & 3.81 & 0.56 & 0.50 & 0.63 & 233 & 0.46 \\
\hline 44 & 31.5 . & $14: 58$ & 2,21 & 0.70 & 4.69 & 15.4 & 39 & 3.74 & 0.56 & 1.00 & 0.64 & 274 & 0.49 \\
\hline 45 & 31.5. & $15: 19$ & 2.16 & 0.60 & 4.44 & 15.9 & 39 & 3.66 & 0.56 & 0.50 & 0.64 & 229 & 0.49 \\
\hline 46 & 31.5. & $15: 58$ & 2.33 & 0.09 & 0.84 & 14.2 & 39 & 6.16 & 0.56 & 0.50 & 0.63 & 236 & 0.57 \\
\hline 47 & 2.6 & $13: 40$ & 3.42 & 0.59 & 2.07 & 15.3 & 21 & 9.64 & 0.73 & 0.08 & 0.61 & 217 & 0.37 \\
\hline 48 & 2.6. & $13: 52$ & 3.41 & 0.53 & 1.92 & 15.4 & 21 & 10.00 & 0.77 & 0.09 & 0.60 & 224 & 0.39 \\
\hline 49 & 2.6 . & $14: 06$ & 3.38 & 0.32 & 1.22 & 15.1 & 20 & 10.48 & 0.81 & 0.09 & 0.60 & 227 & 0.42 \\
\hline 50 & 4.6. & $8: 54$ & 2.54 & 0.90 & 4.67 & 14.7 & 38 & 3.16 & 0.21 & 0.20 & 0.50 & 191 & 0.18 \\
\hline 51 & 4.6. & $10: 15$ & 2.48 & 1.34 & 5.69 & 15.4 & 41 & 3.01 & 0.44 & 0.20 & 0.50 & 191 & 0.25 \\
\hline 52 & 4.6. & $10: 24$ & 2.37 & 1.37 & 5.78 & 15.8 & 41 & 3.04 & 0.47 & 0.20 & 0.50 & 191 & 0.27 \\
\hline 53 & 4.6. & $10: 34$ & 2.33 & 1.57 & 6.44 & 16.0 & 41 & 3.07 & 0.50 & 0.20 & 0.50 & 191 & 0.28 \\
\hline 54 & 4.6. & $11: 31$ & 2.22 & 1.50 & 5.85 & 15.9 & 41 & 3.14 & 0.42 & 0.20 & 0.50 & 183 & 0.31 \\
\hline 55 & 4.6. & $11: 50$ & 2.31 & 0.97 & 3.77 & 15.6 & 41 & 3.10 & 0.35 & 0.20 & 0.50 & 189 & 0.30 \\
\hline 56 & 4.6. & $12: 08$ & 2.30 & 1.53 & 6.06 & 16.2 & 41 & 3.07 & 0.50 & 0.20 & 0.50 & 182 & 0.31 \\
\hline 57 & 4.6. & $12: 16$ & 2.30 & 1.55 & 6.17 & 16.5 & 41 & 3.22 & 0.57 & 0.20 & 0.50 & 184 & 0.32 \\
\hline 58 & 4.6. & $12: 30$ & 2.31 & 1.47 & 6.05 & 16.7 & 42 & 3.39 & 0.66 & 0.21 & 0.47 & 185 & 0.35 \\
\hline 59 & 4.6. & $12: 41$ & 2.30 & 1.62 & 6.75 & 17.0 & 41 & 3.54 & 0.75 & 0.20 & 0.47 & 185 & 0.35 \\
\hline 60 & 4.6. & $12: 57$ & 2.33 & 0.78 & 3.07 & 16.6 & 41 & 3.77 & 0.72 & 0.20 & 0.48 & 185 & 0.40 \\
\hline 61 & 4.6. & $13: 05$ & 2.64 & 0.97 & 4.21 & 14.6 & 41 & 3.67 & 0.70 & 0.19 & 0.48 & 191 & 0.39 \\
\hline 62 & 4.6. & $13: 19$ & 2.83 & 0.54 & 2.13 & 14.4 & 41 & 3.45 & 0.68 & 0.18 & 0.49 & 182 & 0.36 \\
\hline 63 & 5.6. & $11: 54$ & 2.17 & 1.14 & 4.77 & 14.9 & 41 & 3.05 & 0.40 & 0.09 & 1.23 & 170 & 0.50 \\
\hline 64 & 5.6. & $12: 18$ & 2.12 & 1.34 & 5.64 & 14.0 & 43 & 2.87 & 0.43 & 0.09 & 1.10 & 173 & 0.47 \\
\hline 65 & 5.6. & $12: 40$ & 2.04 & 1.38 & 5.94 & 15.0 & 45 & 2.70 & 0.46 & 0.09 & 1.07 & 167 & 0.54 \\
\hline 66 & 5.6. & $12: 53$ & 2.08 & 0.96 & 4.31 & 15.4 & 46 & 2.59 & 0.47 & 0.09 & 1.00 & 167 & 0.59 \\
\hline 67 & 5.6. & $13: 04$ & 2.17 & 0.45 & 2.11 & 14.4 & 46 & 2.59 & 0.48 & 0.09 & 0.99 & 173 & 0.61 \\
\hline 68 & 5.6. & $13: 52$ & 2.14 & 0.94 & 4.75 & 15.7 & 46 & 2.71 & 0.62 & 0.09 & 0.82 & 167 & 0.74 \\
\hline 69 & 5.6. & $14: 03$ & 2.11 & 1.10 & 6.14 & 15.9 & 45 & 2.73 & 0.70 & 0.09 & 0.78 & 168 & 0.70 \\
\hline & 2.43 & 0.97 & 4.30 & 16.7 & 45 & 3.96 & 0.73 & 0.22 & 0.70 & 204 & 0.57 \\
\hline
\end{tabular}

(a) in units of $10^{17} \mathrm{~cm}^{-3}$

(b) in units of $10^{-5} \mathrm{~s}^{-1}\left(\mathrm{~J}\left(\mathrm{NO}_{2}\right)=J_{15}\right)$

(c) in units of $10^{-3} \mathrm{~s}^{-1}\left(\mathrm{~J}\left(\mathrm{O}_{3}\right)=\mathrm{J}_{1}\right)$

(d) in units of $\mathrm{ppb}$

* marks estimates

1) All parameters were measured locally at one end of the absorption path of the $\mathrm{OH}$ measurement with the exception of $\mathrm{O}_{3}, \mathrm{NO}_{2}$, and $\mathrm{HCHO}$, which were measured by differential absorption spectroscopy probing the same volume of air as the $\mathrm{OH}$ measurement. 
Table 2: Relations used to calculate the model input data for the hydrocarbons. Units of ppb are used.

\begin{tabular}{|c|c|c|c|}
\hline species" & relation & error & $r$ \\
\hline $\operatorname{ETH}\left(\mathrm{C}_{2} \mathrm{H}_{6}\right)$ & $2+0.3 \cdot \mathrm{C}_{3} \mathrm{H}_{8}$ & 1.5 & 0.86 \\
\hline $\mathrm{HC}^{2)}$ & $3.0 \cdot \mathrm{C}_{3} \mathrm{H}_{8}$ & 1.5 & 0.84 \\
\hline $\mathrm{HC}^{32}$ & $1.5 \cdot C_{3} H_{8}$ & 1.5 & 0.33 \\
\hline $\mathrm{OL2}\left(\mathrm{C}_{2} \mathrm{H}_{4}\right)^{7}$ & a. $\mathrm{C}_{3} \mathrm{H}_{8}$ & 2.0 & 0.20 \\
\hline $\mathrm{OLT}^{47}$ & $0.3 \cdot \mathrm{C}_{2} \mathrm{H}_{4}$ & 2.0 & -0.07 \\
\hline$T^{2} L^{5}$ & $0.3 \cdot \mathrm{C}_{2} \mathrm{H}_{4}$ & 2.0 & -0.3 \\
\hline$X Y L^{6)}$ & $0.1 \cdot \mathrm{TOL}$ & 2.0 & -0.53 \\
\hline$\overline{\text { PAN }}$ & $0.003 \cdot \mathrm{NO}_{2} \cdot \mathrm{O}_{3} / \mathrm{ppb}$ & 2.0 & 0.29 \\
\hline
\end{tabular}

1) RADM2 species. Chemical notation in brackets.

2) Alkanes with $\mathrm{OH}$ rate constant (298.1 atm) between $2.7 \cdot 10^{-13}$ and $3.4 \cdot 10^{-12} \mathrm{~cm}^{3} \mathrm{~s}^{-4}$

3) Alkanes with $\mathrm{OH}$ rate constant $(298.1 \mathrm{~atm})$ between $3.4 \cdot 10^{-12}$ and $6.8 \cdot 10^{-12} \mathrm{~cm}^{3} \mathrm{~s}^{-1}$

4) Terminal alkenes

5) Toluene and less reactive aromatics

6) Xylene and more reactive aromatics

$\pi \quad 1984: a=2,1983,1987,1988: a=1$ 


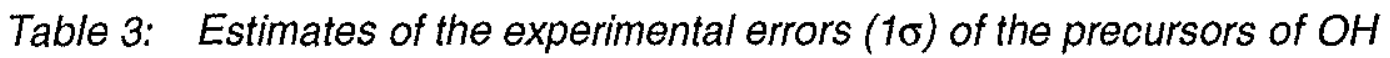

\begin{tabular}{|l|c|c|c|c|}
\hline precursor & $\begin{array}{r}\text { individual } \\
\text { experimental error }\end{array}$ & $\begin{array}{c}\text { other individual } \\
\text { errors }\end{array}$ & $\begin{array}{c}\text { systematic } \\
\text { experimental } \\
\text { error }\end{array}$ & $\begin{array}{c}\text { other } \\
\text { systematic } \\
\text { errors }\end{array}$ \\
\hline $\mathrm{J}\left(\mathrm{O}^{\prime} \mathrm{D}\right)^{1)}$ & $6 \%$ & $<30 \%$ & $26 \%$ & - \\
\hline $\mathrm{J}\left(\mathrm{NO}_{2}\right)^{2)}$ & $2 \%$ & $<30 \%$ & $12 \%$ & - \\
\hline $\mathrm{T}$ & $0.1 \mathrm{~K}$ & $1 \mathrm{~K}$ & - & $3 \mathrm{~K}$ \\
\hline $\mathrm{H}_{2} \mathrm{O}$ & $5 \%$ & - & - & $10 \%$ \\
\hline $\mathrm{O}_{3}$ & $<10 \%$ & $<10 \%$ & $2 \%$ & - \\
\hline $\mathrm{NO}_{2}$ & $<30 \%$ & $<30 \%$ & $5 \%$ & - \\
\hline $\mathrm{HCHO}^{2}$ & $30 \%$ & $<$ factor 1.5 & - & - \\
\hline $\mathrm{CH}_{3} \mathrm{CHO}$ & $30 \%$ & $<$ factor 2 & - & - \\
\hline $\mathrm{PAN}^{2}$ & $2 \%$ & $20 \%$ & $6 \%$ & - \\
\hline $\mathrm{CO}$ & $<10 \%$ & $<$ factor 2 & $10 \%$ & - \\
\hline $\mathrm{C}_{3} \mathrm{H}_{8}$ & $30 \%$ & $<$ factor 2 & $10 \%$ & - \\
\hline
\end{tabular}

\footnotetext{
1) $J\left(O^{\prime} D\right)=J_{1}$

2) $\mathrm{J}\left(\mathrm{NO}_{2}\right)=J_{15}$
} 
Table 4: Sensitivity coefficients (eq(11)) of $\mathrm{OH}$ with respect to various parameters for data from all campaigns.

\begin{tabular}{|c|c|c|c|c|c|c|c|c|c|c|c|}
\hline No & $\mathrm{NO}_{2}$ & $\mathrm{O}_{3}$ & CO & $\mathrm{H}_{2} \mathrm{O}$ & $\mathrm{OL} 2$ & $\mathrm{HCHO}$ & ALD & PAN & $\mathrm{J}\left(\mathrm{NO}_{2}\right)$ & $\mathrm{J}\left(\mathrm{O}_{3}\right)$ & $\mathrm{J}(\mathrm{HCHO})$ \\
\hline \multicolumn{12}{|c|}{ 1983 Deuselbach } \\
\hline 1 & -0.59 & 0.43 & -0.04 & 0.53 & 0.00 & 0.26 & -0.17 & 0.05 & 0.18 & 0.59 & 0.26 \\
\hline 2 & -0.96 & 0.31 & 0.00 & 0.46 & 0.00 & 0.22 & .0 .03 & 0.26 & 0.18 & 0.48 & 0.22 \\
\hline 3 & -0.86 & 0.39 & -0.01 & 0.51 & 0.00 & 0.25 & 0.08 & 0.16 & 0.16 & 0.54 & 0.25 \\
\hline 4 & .0 .39 & 0.20 & -0.08 & 0.42 & -0.01 & 0.28 & -0.19 & 0.08 & 0.29 & 0.47 & 0.29 \\
\hline 5 & .0 .11 & 0.30 & -0.20 & 0.56 & -0.02 & 0.09 & 0.09 & 0.02 & 0.40 & 0.64 & 0.10 \\
\hline 6 & 0.27 & 0.07 & -0.31 & 0.46 & -0.03 & 0.07 & -0.09 & 0.02 & 0.56 & 0.54 & 0.09 \\
\hline 7 & 0.22 & 0.06 & $\cdot 0.28$ & 0.45 & -0.03 & 0.10 & -0.09 & 0.02 & 0.54 & 0.52 & 0.11 \\
\hline 8 & -0.41 & 0.36 & $\cdot 0.10$ & 0.56 & -0.01 & 0.15 & -0.13 & 0.07 & 0.29 & 0.62 & 0.15 \\
\hline 9 & -0.27 & 0.29 & -0.11 & 0.54 & -0.01 & 0.13 & 0.16 & 0.07 & 0.35 & 0.60 & 0.14 \\
\hline \multicolumn{12}{|c|}{1984 Schauinsland } \\
\hline 10 & 0.55 & -0.07 & -0.37 & 0.36 & -0.08 & 0.06 & -0.02 & 0.00 & 0.67 & 0.44 & 0.10 \\
\hline 11 & 0.40 & $\cdot 0.03$ & -0.29 & 0.39 & $\cdot 0.08$ & 0.09 & -0.03 & 0.00 & 0.62 & 0.45 & 0.12 \\
\hline 12 & -0.01 & 0.25 & -0.19 & 0.55 & -0.05 & 0.08 & -0.05 & 0.01 & 0.44 & 0.61 & 0.09 \\
\hline 13 & 0.22 & 0.11 & -0.24 & 0.48 & -0.06 & 0.08 & -0.06 & 0.00 & 0.54 & 0.54 & 0.09 \\
\hline 14 & 0.45 & $\cdot 0.02$ & -0.30 & 0.40 & $\cdot 0.08$ & 0.07 & -0.05 & 0.00 & 0.63 & 0.47 & 0.10 \\
\hline 15 & 0.48 & -0.06 & -0.30 & 0.37 & -0.08 & 0.08 & -0.06 & 0.00 & 0.65 & 0.44 & 0.12 \\
\hline 16 & 0.32 & $\cdot 0.04$ & -0.26 & 0.36 & -0.07 & 0.14 & -0.07 & 0.01 & 0.59 & 0.44 & 0.17 \\
\hline 17 & .0 .45 & 0.38 & .0 .09 & 0.53 & .0 .02 & 0.22 & -0.08 & 0.03 & 0.25 & 0.59 & 0.23 \\
\hline \multicolumn{12}{|c|}{1987 Jülich } \\
\hline 18 & .0 .77 & 0.41 & -0.01 & 0.55 & 0.00 & 0.15 & $\cdot 0.11$ & 0.18 & 0.21 & 0.60 & 0.15 \\
\hline 19 & .0 .69 & 0.38 & -0.02 & 0.54 & 0.00 & 0.13 & -0.13 & 0.18 & 0.24 & 0.60 & 0.14 \\
\hline 20 & -0.67 & 0.29 & -0.02 & 0.48 & 0.00 & 0.17 & -0.15 & 0.21 & 0.27 & 0.53 & 0.18 \\
\hline 21 & -0.65 & 0.21 & -0.02 & 0.43 & 0.00 & 0.21 & -0.16 & 0.22 & 0.29 & 0.48 & 0.21 \\
\hline 22 & -0.59 & 0.14 & -0.02 & 0.39 & .0 .01 & 0.23 & -0.18 & 0.23 & 0.32 & 0.43 & 0.23 \\
\hline 23 & -0.77 & 0.31 & -0.01 & 0.48 & 0.00 & 0.16 & -0.12 & 0.24 & 0.25 & 0.54 & 0.16 \\
\hline 24 & $\cdot 0.74$ & 0.32 & -0.01 & 0.49 & 0.00 & 0.18 & -0.13 & 0.20 & 0.24 & 0.54 & 0.19 \\
\hline 25 & 0.61 & 0.34 & -0.02 & 0.50 & -0.01 & 0.21 & -0.16 & 0.14 & 0.24 & 0.55 & 0.22 \\
\hline 26 & -0.57 & 0.35 & .0 .03 & 0.52 & $\cdot 0.01$ & 0.17 & -0.17 & 0.14 & 0.26 & 0.58 & 0.17 \\
\hline 27 & 0.68 & 0.25 & -0.02 & 0.45 & 0.00 & 0.18 & -0.14 & 0.22 & 0.28 & 0.51 & 0.19 \\
\hline 28 & .0 .74 & 0.48 & -0.02 & 0.58 & 0.00 & 0.45 & -0.12 & 0.13 & 0.19 & 0.65 & 0.15 \\
\hline 29 & -0.44 & 0.42 & .0 .05 & 0.58 & -0.01 & 0.11 & -0.16 & 0.08 & 0.27 & 0.66 & 0.12 \\
\hline 30 & -0.28 & 0.36 & .0 .08 & 0.57 & -0.02 & 0.09 & -0.17 & 0.07 & 0.33 & 0.65 & 0.10 \\
\hline 31 & $\cdot 0.20$ & 0.28 & -0.09 & 0.53 & -0.03 & 0.09 & -0.17 & 0.08 & 0.37 & 0.61 & 0.11 \\
\hline 32 & -0.31 & 0.31 & -0.07 & 0.53 & $\cdot 0.02$ & 0.11 & -0.16 & 0.09 & 0.34 & 0.61 & 0.12 \\
\hline 33 & .0 .36 & 0.31 & .0 .07 & 0.53 & -0.02 & 0.10 & .0 .16 & 0.11 & 0.34 & 0.61 & 0.12 \\
\hline 34 & .0 .24 & 0.23 & -0.09 & 0.48 & -0.02 & 0.10 & -0.16 & 0.11 & 0.39 & 0.57 & 0.12 \\
\hline \multicolumn{12}{|c|}{1988 Jülich } \\
\hline 35 & -0.13 & $\cdot 0.07$ & -0.15 & 0.34 & -0.02 & 0.13 & -0.07 & 0.16 & 0.53 & 0.40 & 0.17 \\
\hline 36 & .0 .26 & .0 .10 & -0.12 & 0.33 & -0.01 & 0.14 & 0.07 & 0.22 & 0.53 & 0.39 & 0.17 \\
\hline 37 & $\cdot 0.02$ & $\cdot 0.23$ & -0.19 & 0.28 & -0.02 & 0.10 & -0.07 & 0.21 & 0.65 & 0.35 & 0.14 \\
\hline 38 & .0 .11 & .0 .26 & -0.16 & 0.26 & -0.03 & 0.12 & -0.07 & 0.25 & 0.65 & 0.32 & 0.15 \\
\hline 39 & -0.07 & $\cdot 0.38$ & .0 .16 & 0.16 & $\cdot 0.04$ & 0.14 & -0.05 & 0.27 & 0.71 & 0.22 & 0.17 \\
\hline 40 & -1.02 & 0.64 & 0.00 & 0.64 & 0.00 & 0.25 & 0.00 & 0.06 & 0.05 & 0.68 & 0.25 \\
\hline 41 & -1.02 & 0.62 & 0.00 & 0.62 & 0.00 & 0.26 & 0.00 & 0.06 & 0.05 & 0.66 & 0.26 \\
\hline 42 & .0 .99 & 0.58 & 0.00 & 0.61 & 0,00 & 0.25 & -0.02 & 0.09 & 0.07 & 0.64 & 0.25 \\
\hline 43 & .0 .89 & 0.39 & 0.00 & 0.49 & 0.00 & 0.24 & -0.07 & 0.17 & 0.16 & 0.53 & 0.24 \\
\hline 44 & .0 .79 & 0.32 & -0.01 & 0.46 & 0.00 & 0.23 & -0.13 & 0.17 & 0.19 & 0.49 & 0.23 \\
\hline 45 & $\cdot 0.88$ & 0.30 & -0.01 & 0.44 & 0.00 & 0.25 & $-0,08$ & 0.20 & 0.19 & 0.47 & 0.25 \\
\hline 46 & -0.91 & 0.25 & -0.01 & 0.36 & 0.01 & 0.24 & -0.05 & 0.22 & 0.23 & 0.39 & 0.24 \\
\hline
\end{tabular}


(table 4 continued)

\begin{tabular}{cccccccccccc}
\hline $\mathrm{No}$ & $\mathrm{NO}_{2}$ & $\mathrm{O}_{3}$ & $\mathrm{CO}$ & $\mathrm{H}_{2} \mathrm{O}$ & $\mathrm{OL} 2$ & $\mathrm{HCHO}$ & $\mathrm{ALD}$ & $\mathrm{PAN}$ & $\mathrm{J}\left(\mathrm{NO}_{2}\right)$ & $J\left(\mathrm{O}_{3}\right)$ & $J(\mathrm{HCHO})$ \\
\hline 47 & -1.03 & 0.42 & 0.00 & 0.49 & 0.00 & 0.27 & 0.00 & 0.17 & 0.13 & 0.54 & 0.27 \\
48 & -1.03 & 0.37 & 0.00 & 0.46 & 0.00 & 0.28 & 0.00 & 0.19 & 0.15 & 0.51 & 0.28 \\
49 & -1.02 & 0.28 & 0.00 & 0.41 & 0.00 & 0.29 & 0.00 & 0.22 & 0.19 & 0.45 & 0.29 \\
50 & -0.95 & 0.72 & 0.00 & 0.73 & 0.00 & 0.11 & -0.03 & 0.07 & 0.07 & 0.78 & 0.11 \\
51 & -0.93 & 0.66 & -0.01 & 0.68 & 0.00 & 0.17 & -0.04 & 0.07 & 0.08 & 0.73 & 0.17 \\
52 & -0.93 & 0.64 & -0.01 & 0.67 & 0.00 & 0.18 & -0.04 & 0.07 & 0.08 & 0.72 & 0.18 \\
53 & -0.93 & 0.63 & -0.01 & 0.66 & 0.00 & 0.19 & -0.04 & 0.07 & 0.08 & 0.71 & 0.19 \\
54 & -0.94 & 0.65 & -0.01 & 0.68 & 0.00 & 0.16 & -0.04 & 0.08 & 0.09 & 0.73 & 0.16 \\
55 & -0.92 & 0.66 & -0.01 & 0.70 & 0.00 & 0.13 & -0.05 & 0.09 & 0.10 & 0.75 & 0.13 \\
56 & -0.93 & 0.63 & -0.01 & 0.66 & 0.00 & 0.18 & -0.04 & 0.08 & 0.09 & 0.71 & 0.18 \\
57 & -0.94 & 0.60 & -0.01 & 0.64 & 0.00 & 0.20 & -0.04 & 0.09 & 0.09 & 0.69 & 0.20 \\
58 & -0.94 & 0.57 & -0.01 & 0.61 & 0.00 & 0.22 & -0.04 & 0.10 & 0.10 & 0.66 & 0.22 \\
59 & -0.95 & 0.55 & -0.01 & 0.59 & 0.00 & 0.25 & -0.04 & 0.10 & 0.09 & 0.63 & 0.25 \\
60 & -0.94 & 0.51 & -0.01 & 0.58 & 0.00 & 0.23 & -0.04 & 0.12 & 0.12 & 0.62 & 0.23 \\
61 & -0.95 & 0.59 & -0.01 & 0.62 & 0.00 & 0.22 & -0.04 & 0.08 & 0.09 & 0.67 & 0.22 \\
62 & -0.91 & 0.60 & -0.01 & 0.63 & 0.00 & 0.20 & -0.04 & 0.07 & 0.10 & 0.69 & 0.20 \\
63 & -0.96 & 0.58 & -0.01 & 0.65 & 0.00 & 0.15 & -0.02 & 0.13 & 0.12 & 0.69 & 0.15 \\
64 & -0.95 & 0.62 & -0.01 & 0.67 & 0.00 & 0.16 & -0.02 & 0.10 & 0.09 & 0.71 & 0.17 \\
65 & -0.93 & 0.57 & -0.01 & 0.64 & 0.00 & 0.17 & -0.02 & 0.12 & 0.12 & 0.68 & 0.17 \\
66 & -0.90 & 0.50 & -0.02 & 0.61 & 0.00 & 0.16 & -0.03 & 0.15 & 0.16 & 0.65 & 0.16 \\
67 & -0.86 & 0.47 & -0.02 & 0.60 & 0.00 & 0.16 & -0.03 & 0.14 & 0.19 & 0.65 & 0.16 \\
68 & -0.91 & 0.40 & -0.01 & 0.54 & 0.00 & 0.20 & -0.03 & 0.18 & 0.18 & 0.57 & 0.21 \\
69 & -0.93 & 0.39 & -0.01 & 0.51 & 0.00 & 0.24 & -0.02 & 0.18 & 0.16 & 0.55 & 0.24
\end{tabular}


Table 5: Sensitivity coefficients of the calculated $\mathrm{OH}$ with respect to several reaction rate constants (see section 2)

\begin{tabular}{|c|c|c|c|c|c|c|c|c|c|c|c|}
\hline No & R2b & $\mathrm{R} 2 \mathrm{a}$ & R3 & R16 & $\mathrm{R} 6$ & R11 & $\mathrm{R} 13$ & $\mathrm{R} 14$ & $\mathrm{R} 12$ & R4 & R5 \\
\hline 1 & -0.39 & -0.16 & 0.54 & 0.17 & 0.08 & .0 .19 & .0 .09 & 0.05 & 0.09 & 0.71 & -0.04 \\
\hline 2 & -0.33 & -0.13 & 0.46 & .0 .18 & 0.00 & .0 .06 & -0.18 & 0.26 & 0.18 & .0 .96 & 0.00 \\
\hline 3 & -0.36 & -0.15 & 0.51 & $\cdot 0.16$ & 0.01 & -0.11 & -0.14 & 0.16 & 0.14 & -0.89 & -0.01 \\
\hline 4 & -0.32 & -0.13 & 0.44 & $\cdot 0.28$ & 0.14 & -0.23 & -0.12 & 0.08 & 0.12 & .0 .58 & -0.08 \\
\hline 5 & $\cdot 0.43$ & .0 .18 & 0.60 & -0.36 & 0.28 & -0.10 & -0.04 & 0.03 & 0.04 & -0.48 & $\cdot 0.20$ \\
\hline 6 & -0.36 & -0.15 & 0.51 & 0.50 & 0.40 & -0.09 & -0.03 & 0.02 & 0.03 & -0.26 & .0 .31 \\
\hline 7 & -0.35 & .0 .14 & 0.50 & -0.50 & 0.39 & -0.10 & -0.04 & 0.02 & 0.04 & -0.29 & -0.28 \\
\hline 8 & -0.42 & $\cdot 0.17$ & 0.58 & $\cdot 0.27$ & 0.15 & -0.15 & -0.09 & 0.07 & 0.09 & -0.62 & -0.10 \\
\hline 9 & -0.40 & .0 .16 & 0.56 & .0 .32 & 0.19 & -0.18 & -0.10 & 0.07 & 0.10 & -0.54 & -0.11 \\
\hline 10 & -0.30 & .0 .12 & 0.41 & .0 .54 & 0.44 & -0.03 & 0.00 & 0.00 & 0.00 & $\cdot 0.11$ & .0 .37 \\
\hline 11 & -0.31 & -0.13 & 0.43 & 0.50 & 0.41 & -0.03 & -0.01 & 0.00 & 0.01 & -0.21 & -0.29 \\
\hline 12 & $\cdot 0.42$ & .0 .17 & 0.58 & -0.38 & 0.30 & -0.06 & -0.02 & 0.01 & 0.02 & -0.43 & -0.19 \\
\hline 13 & -0.37 & -0.15 & 0.51 & $\cdot 0.44$ & 0.35 & .0 .06 & -0.02 & 0.00 & 0.02 & -0.31 & -0.24 \\
\hline 14 & -0.32 & -0.13 & 0.44 & -0.51 & 0.41 & -0.06 & -0.01 & 0.00 & 0.01 & -0.17 & $\cdot 0.30$ \\
\hline 15 & -0.30 & .0 .12 & 0.42 & -0.53 & 0.42 & -0.06 & -0.01 & 0.00 & 0.01 & .0 .15 & -0.30 \\
\hline 16 & -0.30 & .0 .12 & 0.41 & $\cdot 0.52$ & 0.41 & -0.08 & 0.02 & 0.01 & 0.02 & -0.25 & -0.26 \\
\hline 17 & -0.39 & -0.16 & 0.55 & .0 .22 & 0.16 & -0.09 & -0.04 & 0.03 & 0.04 & -0.68 & -0.09 \\
\hline 18 & .0 .40 & .0 .16 & 0.55 & -0.20 & 0.03 & -0.14 & -0.17 & 0.18 & 0.17 & -0.82 & -0.01 \\
\hline 19 & -0.39 & -0.16 & 0.55 & -0.23 & 0.05 & -0.15 & -0.18 & 0.18 & 0.17 & -0.77 & 0.02 \\
\hline 20 & -0.35 & -0.14 & 0.49 & -0.26 & 0.05 & -0.17 & -0.20 & 0.21 & 0.20 & -0.75 & -0.02 \\
\hline 21 & -0.31 & .0 .13 & 0.44 & $\cdot 0.28$ & 0.05 & $\cdot 0.18$ & -0.21 & 0.22 & 0.21 & -0.74 & $\cdot 0.02$ \\
\hline 22 & -0.28 & .0 .12 & 0.39 & -0.30 & 0.07 & -0.20 & -0.23 & 0.23 & 0.22 & -0.70 & -0.02 \\
\hline 23 & -0.35 & $\cdot 0.14$ & 0.49 & -0.25 & 0.02 & .0 .15 & -0.22 & 0.24 & 0.21 & .0 .82 & $\cdot 0.01$ \\
\hline 24 & -0.35 & -0.14 & 0.49 & -0.23 & 0.03 & -0.16 & -0.19 & 0.21 & 0.19 & -0.79 & -0.01 \\
\hline 25 & .0 .36 & -0.15 & 0.50 & -0.22 & 0.06 & -0.19 & 0.16 & 0.14 & 0.16 & -0.71 & -0.02 \\
\hline 26 & -0.38 & -0.16 & 0.53 & -0.24 & 0.07 & $\cdot 0.20$ & -0.16 & 0.14 & 0.16 & .0 .69 & $\cdot 0.03$ \\
\hline 27 & -0.33 & -0.14 & 0.46 & -0.27 & 0.05 & -0.15 & -0.21 & 0.22 & 0.20 & 0.77 & .0 .02 \\
\hline 28 & $\cdot 0.42$ & -0.17 & 0.59 & -0.18 & 0.04 & .0 .14 & -0.14 & 0.13 & 0.13 & .0 .81 & -0.02 \\
\hline 39 & .0 .43 & .0 .18 & 0.60 & $\cdot 0.25$ & 0.13 & -0.17 & .0 .10 & 0.08 & 0.10 & -0.63 & -0.05 \\
\hline 30 & -0.42 & -0.17 & 0.59 & -0.30 & 0.18 & -0.18 & -0.09 & 0.07 & 0.09 & -0.54 & -0.08 \\
\hline 31 & .0 .40 & -0.16 & 0.56 & -0.34 & 0.21 & -0.18 & -0.09 & 0.08 & 0.09 & .0 .50 & -0.09 \\
\hline 32 & -0.40 & .0 .16 & 0.55 & $\cdot 0.31$ & 0.17 & -0.17 & -0.11 & 0.10 & 0.11 & .0 .57 & $\cdot 0.07$ \\
\hline 33 & -0.39 & -0.16 & 0.55 & -0.31 & 0.16 & -0.17 & -0.12 & 0.11 & 0.12 & -0.59 & $\cdot 0.07$ \\
\hline 34 & -0.37 & -0.15 & 0.51 & -0.36 & 0.20 & -0.18 & -0.12 & 0.11 & 0.12 & -0.53 & -0.09 \\
\hline 35 & $\cdot 0.27$ & $\cdot 0.11$ & 0.37 & $\cdot 0.48$ & 0.28 & -0.08 & -0.15 & 0.17 & 0.16 & .0 .53 & $\cdot 0.15$ \\
\hline 36 & -0.26 & -0.11 & 0.36 & $\cdot 0.49$ & 0.24 & -0.08 & -0.21 & 0.22 & 0.21 & -0.61 & $\cdot 0.12$ \\
\hline 37 & -0.23 & -0.09 & 0.32 & -0.59 & 0.32 & -0.08 & -0.20 & 0.21 & 0.20 & .0 .48 & -0.19 \\
\hline 38 & -0.21 & .0 .09 & 0.30 & -0.60 & 0.29 & $\cdot 0.07$ & $\cdot 0.24$ & 0.25 & 0.24 & -0.54 & .0 .16 \\
\hline 39 & -0.15 & -0.06 & 0.20 & -0.67 & 0.31 & -0.06 & -0.27 & 0.27 & 0.27 & -0.53 & $\cdot 0.16$ \\
\hline 40 & -0.46 & .0 .19 & 0.64 & -0.05 & 0.00 & -0.01 & -0.04 & 0.06 & 0.04 & -1.02 & 0.00 \\
\hline 41 & -0.45 & -0.18 & 0.62 & -0.05 & 0.00 & -0.01 & -0.04 & 0.06 & 0.04 & -1.02 & 0.00 \\
\hline 42 & -0.44 & 0.18 & 0.61 & -0.07 & 0.00 & -0.03 & .0 .07 & 0.09 & 0.07 & .0 .99 & 0.00 \\
\hline 43 & $\cdot 0.36$ & $\cdot 0.15$ & 0.49 & .0 .16 & 0.01 & -0.11 & -0.15 & 0.17 & 0.15 & $\cdot 0.90$ & 0.00 \\
\hline 44 & -0.33 & -0.14 & 0.46 & -0.19 & 0.01 & -0.20 & -0.18 & 0.17 & 0.18 & -0.80 & -0.01 \\
\hline 45 & -0.32 & -0.13 & 0.44 & -0.19 & 0.01 & -0.11 & -0.18 & 0.20 & 0.18 & -0.89 & .0 .01 \\
\hline 46 & -0.26 & -0.10 & 0.36 & -0.23 & 0.01 & -0.09 & -0.22 & 0.22 & 0.21 & -0.92 & -0.01 \\
\hline 47 & -0.35 & -0.14 & 0.49 & -0.13 & 0.00 & -0.01 & -0.13 & 0.17 & 0.13 & -1.03 & 0.00 \\
\hline 48 & -0.33 & -0.13 & 0.46 & -0.15 & 0.00 & -0.01 & -0.15 & 0.19 & 0.15 & -1.03 & 0.00 \\
\hline 49 & $\cdot 0.30$ & $\cdot 0.12$ & 0.41 & -0.19 & 0.00 & -0.01 & -0.19 & 0.22 & 0.18 & -1.03 & 0.00 \\
\hline 50 & .0 .52 & .0 .21 & 0.73 & .0 .07 & 0.01 & -0.05 & -0.06 & 0.07 & 0.06 & -0.96 & 0.00 \\
\hline
\end{tabular}


(table 5 continued)

\begin{tabular}{cccccccccccc}
\hline No & R2b & R2a & R3 & R16 & R6 & R11 & R13 & R14 & R12 & R4 & R5 \\
\hline 51 & -0.49 & -0.20 & 0.68 & -0.08 & 0.01 & -0.05 & -0.06 & 0.07 & 0.06 & -0.95 & -0.01 \\
52 & -0.48 & -0.20 & 0.67 & -0.08 & 0.01 & -0.05 & -0.07 & 0.07 & 0.07 & -0.95 & -0.01 \\
53 & -0.48 & -0.19 & 0.66 & -0.08 & 0.01 & -0.05 & -0.07 & 0.07 & 0.07 & -0.95 & -0.01 \\
54 & -0.49 & -0.20 & 0.68 & -0.09 & 0.01 & -0.05 & -0.07 & 0.08 & 0.07 & -0.96 & -0.01 \\
55 & -0.51 & -0.21 & 0.70 & -0.10 & 0.02 & -0.06 & -0.08 & 0.09 & 0.08 & -0.94 & -0.01 \\
56 & -0.48 & -0.20 & 0.66 & -0.09 & 0.01 & -0.05 & -0.07 & 0.08 & 0.07 & -0.95 & -0.01 \\
57 & -0.46 & -0.19 & 0.64 & -0.09 & 0.01 & -0.05 & -0.08 & 0.09 & 0.07 & -0.96 & -0.01 \\
58 & -0.44 & -0.18 & 0.61 & -0.09 & 0.01 & -0.05 & -0.08 & 0.10 & 0.08 & -0.96 & -0.01 \\
59 & -0.43 & -0.17 & 0.59 & -0.09 & 0.01 & -0.05 & -0.08 & 0.10 & 0.08 & -0.97 & -0.01 \\
60 & -0.42 & -0.17 & 0.58 & -0.12 & 0.01 & -0.05 & -0.11 & 0.12 & 0.11 & -0.96 & -0.01 \\
61 & -0.44 & -0.18 & 0.62 & -0.09 & 0.01 & -0.05 & -0.08 & 0.09 & 0.07 & -0.97 & -0.01 \\
62 & -0.45 & -0.19 & 0.63 & -0.10 & 0.02 & -0.05 & -0.07 & 0.08 & 0.07 & -0.94 & -0.01 \\
63 & -0.47 & -0.19 & 0.65 & -0.12 & 0.01 & -0.03 & -0.10 & 0.13 & 0.10 & -0.98 & -0.01 \\
64 & -0.48 & -0.20 & 0.67 & -0.09 & 0.02 & -0.03 & -0.08 & 0.10 & 0.08 & -0.98 & -0.01 \\
65 & -0.46 & -0.19 & 0.64 & -0.12 & 0.02 & -0.03 & -0.09 & 0.12 & 0.09 & -0.97 & -0.01 \\
66 & -0.44 & -0.18 & 0.62 & -0.15 & 0.03 & -0.03 & -0.12 & 0.15 & 0.12 & -0.95 & -0.02 \\
67 & -0.44 & -0.18 & 0.61 & -0.18 & 0.04 & -0.04 & -0.13 & 0.15 & 0.13 & -0.93 & -0.02 \\
68 & -0.39 & -0.16 & 0.54 & -0.18 & 0.03 & -0.03 & -0.15 & 0.19 & 0.14 & -0.96 & -0.01 \\
69 & -0.37 & -0.15 & 0.51 & -0.16 & 0.02 & -0.03 & -0.13 & 0.19 & 0.13 & -0.97 & -0.01
\end{tabular}




\section{References}

Altshuller, A. P., Ambient air hydroxyl radical concentrations: Measurements and model predictions, JAPCA, 39, 704-708, 1989.

Atkinson, R., D. L. Baulch, R. A. Cox, R. F. Hampson, J. A. Kerr, and J. Troe, Evaluated kinetic and photochemical data for atmospheric chemistry: Supplement III, 18, 881-1097, 1989.

Callies, J., Absorptionsspektroskopischer Nachweis von Hydroxyl-Radikalen in der Troposphäre, Thesis, University of Cologne, 1988.

Cox, R. A., M. J. Ruffey, Thermal decomposition of peroxyacetyl nitrate in the presence of nitric oxide, Environ.Sci.Technol., 11, 500-509, 1977.

Comes, F. J., W. Armerding, R. Grigonis, A. Herbert, M. Spiekermann, and J. Walter, Tropospheric OH: Local measurements and their interpretations, Ber. Bunsenges. Phys. Chem., 96, 284-286, 1992.

Dodge, M. C., A comparison of three photochemical oxidant mechanisms, J. Geophys. Res., 94, 5121-5136, 1989.

Dorn, H.-P., J. Callies, U. Platt, D. H. Ehhalt, Measurement of tropospheric $\mathrm{OH}$ concentrations by laser-long path absorption spectroscopy, Tellus, 40B, 437-445, 1988.

Ehhalt, D. H., Chemische Umwandlungen in der Atmosphäre, Proceedings of the 3. Forum der Rheinisch-Westfälischen Akademie der Wissenschaften, Westdeutscher Verlag, p. 21, 1986.

Ehhalt, D. H., Free radicals in the atmosphere, Free Rad. Res. Communs., 3, 153-164, 1987.

Ehhalt, D. H., H.-P.Dorn, D. Poppe, The chemistry of the hydroxyl radical in the troposphere, Proc. Royal. Soc. (Edinburgh), 97B, 17-34, 1991.

Eisele, F. L., and D. J. Tanner, lon-assisted tropospheric $\mathrm{OH}$ measurements, J. Geophys. Res., 96, 9295-9308, 1991.

Felton, C. C., A radiocarbon tracer method for measuring tropospheric OH, PH.D. Thesis, Washington State University, 1988.

Felton, C. C., J. C. Sheppard, and M. J. Campbell, Measurements of the diurnal $\mathrm{OH}$ cycle by a ${ }^{14} \mathrm{C}$-tracer method, Nature, 335, 53-55, 1988.

Felton, C. C., J. C. Sheppard, M. J. Campbell, The radiochemical hydroxyl radical measurement method, Environ. Sci. Technol., 24, 1841-1847, 1990.

Hewitt, C. N., and R. M. Harrison, Tropospheric concentrations of the hydroxyl radical - a review, Atm. Environ., 19, 545-554, 1985. 
Hofzumahaus, A., H.-P. Dorn, J. Callies, U. Platt, D. H. Ehhalt, Tropospheric $\mathrm{OH}$ concentration measurements by laser long-path absorption spectroscopy, Atm. Environ., 25A, 2017-2022, 1991.

Hough, A., An intercomparison of mechanisms for the production of photochemical oxidants, J. Geophys. Res, 93, 3789-3812, 1988.

Junkermann, W., U. Platt, and A. Volz-Thomas, A photoelectric detector for the measurement of photolysis frequencies of ozone and other atmospheric molecules, J. Atmos. Chem., 8, 203-227, 1989.

Levy II, H., Photochemistry of the lower troposphere, Planet. Space Sci., 20, 919-935, 1972.

Levy II, H., Normal atmosphere: Large radical and formaldehyde predicted, Science, 173, 141-143, 1971.

Liu, S. C., M. Trainer, F. C. Fehsenfeld, D. D. Parrish, E. J. Williams, D. W. Fahey, G. Hübler, P. C. Murphy, Ozone production in the rural troposphere and the implications for the regionasl and global ozone distribution, J. Geophs. Res. 92, 4191-4207, 1987.

Logan, J. A., M. J. Prather, S. C. Woisy, and M. B. McElroy, Tropospheric Chemistry: A global perspective, J. Geophys. Res., 86, 7210-7254, 1981.

Martin, R. S., H. Westberg, E. Allwine, L. Ashman, J. C. Farmer, and B. Lamb, Measurement of isoprene and its atmospheric oxidation products in a central pennsylvania deciduous forest, J. Atmos. Chem., 13, 1-32, 1991.

Middleton, P., W. R. Stockwell, W. P. Carter, Aggregation and analysis of volatile organic compounds emissions for regional modelling, Atmos. Environ. 24A, 1107-1133, 1990.

Mount, G. H., The measurement of tropospheric $\mathrm{OH}$ by long path absorption. 1. Instrumentation, J. Geophys. Res., 97, 2427-2444, 1992.

Mozurkewich, M., P. H. McMurry, A. Gupta and J. G. Calvert, Mass accommodation coefficient for $\mathrm{HO}_{2}$ radicals on aqueous particles, J. Geophys. Res. 92, 4163-4170, 1987.

Perner, D., U. Platt, M. Trainer, G. Hübler, J. Drummond, W. Junkermann, J. Rudolph, B. Schubert, A. Volz, D. H. Ehhalt, J. Rumpel, G. Helas, Measurements of tropospheric $\mathrm{OH}$ concentrations: A comparison of field data with model predictions, J. Atm. Chem., 5, 185-216, 1987.

Platt, U., M. Rateike, W. Junkermann, A. Hofzumahaus, D. H. Ehhalt, Detection of atmospheric $\mathrm{OH}$ radicals, Free. Rad. Res. Comms., 3, 165-172, 1987.

Platt, U., M. Rateike, W. Junkermann, J. Rudolph, D. H. Ehhalt, New tropospheric OH measurements, J. Geophys. Res., 93, 5159-5166, 1988.

Poppe, D., M. Wallasch, J. Zimmermann, H.-P. Dorn, D. H. Ehhalt, Comparison of the tropospheric concentration of $\mathrm{OH}$ with model calculations, Ber. Bunsenges.

Phys. Chem., 96, 286-290, 1992. 
Poppe, D., M. Wallasch, J. Zimmermann, The dependence of the concentration of $\mathrm{OH}$ on its precursors under moderately polluted conditions: a model study, J. Atmos. Chem. 16, 61-78, 1993a.

Poppe, D., R. Bauer, T. Brauers, D. Brüning, J. Callies, H.-P. Dorn, A. Hofzumahaus, F.-J. Johnen, A. Khedim, R. Koppmann, H. London, K.-P. Müller, R. Neuroth, Ch. Plaß-Dülmer, U. Platt, F. Rohrer, J. Rudolph, U. Schmidt, M. Wallasch, D. H. Ehhalt, Measurements of atmospheric trace gas concentrations during the $\mathrm{OH}$-campaign in Jülich 1988, Jül-Report 2731, KFA Jülich, D-52425 Jülich, Germany, 1993b.

Röth, E. P., Description of a Photon-Flux Model, Jül-Report, KFA Jülich, D-52425 Jülich, Germany, in preparation, 1992.

Schneeweiß, H., and H. J. Mittag, Lineare Modelle mit fehlerbehafteten Daten, Physica Verlag, Heidelberg, 1986.

Stockwell, W. R., P. Middleton, J. S. Chang, and X. Tang, The second generation regional acid deposition model chemical mechanism for regional air quality modeling, J. Geophys. Res., 95, 16343-16367, 1990.

Thompson, A. M., M. A. Huntley, R. W. Stewart, Perturbations to tropospheric oxidants, 1985-2035, 1. Calculations of ozone and $\mathrm{OH}$ in chemically coherent regions, J. Geophys. Res.,95, 9829-9844, 1990.

Wallasch, M., D. Poppe, D. Brüning, H.-P. Dorn, R. Koppmann, K.-P. Müller, F. Rohrer, J. Rudolph, U. Schmidt, D. H. Ehhalt, Trace gas abundances during a summer period 1988 in Jülich (Germany), Jül-report, in preparation, 1994.

Weinstock, B., H. Niki, and T. Y. Chang, Chemical factors affecting the hydroxyl radical concentration in the troposphere, Adv. Environ. Sci. Technol., 10, 221-258, 1980.

Withby, K. T., The physical characteristics of sulfur aerosols, Atm. Environ., 12, 135-159, 1978. 
Jul-2951

August 1994

ISSN 0944-2952 